\title{
Modifying the Electronic and Optical Properties of Nano ZnS via Doping With Mn and Fe
}

\section{Zein Heiba}

Ain Shams University Faculty of Science

\section{Mohamed Mohamed}

Ain Shams University Faculty of Science

H. El Shimy

Ain Shams University Faculty of Science

Ali Badawi ( $\square$ adaraghmeh@yahoo.com )

Taif University https://orcid.org/0000-0002-3068-9609

\section{Research Article}

Keywords: Nano ZnS, Mn, Fe doping, structure, optical properties, electronic properties

Posted Date: February 19th, 2021

DOl: https://doi.org/10.21203/rs.3.rs-241301/v1

License: (c) (1) This work is licensed under a Creative Commons Attribution 4.0 International License.

Read Full License

Version of Record: A version of this preprint was published at Journal of Materials Science: Materials in Electronics on April 12th, 2021. See the published version at https://doi.org/10.1007/s10854-021-05867w. 


\title{
Modifying the electronic and optical properties of nano $\mathrm{ZnS}$ via doping with Mn and Fe
}

\author{
Zein K. Heiba ${ }^{1}$, Mohamed Bakr Mohamed ${ }^{1,2,}{ }^{*}$, H. El Shimy ${ }^{1}$, Ali Badawi ${ }^{3,4,}$ * \\ ${ }^{1}$ Physics Department, Faculty of Science, Ain Shams University, Cairo, Egypt. \\ ${ }^{2}$ Physics Department, Faculty of Science, Taibah University, Al-Madinah Al-Munawara, \\ Saudi Arabia. \\ ${ }^{3}$ Department of Physics, College of Science, Taif University, P.O. Box 11099, Taif 21944, \\ Saudi Arabia \\ ${ }^{4}$ Department of Physics, University College of Turabah, Taif University, P.O. Box 11099, Taif \\ 21944, Saudi Arabia
}

\begin{abstract}
$5 \% \mathrm{Fe}$ and $\mathrm{Mn}$-doped nano $\mathrm{ZnS}\left(\mathrm{Zn}_{0.95} \mathrm{~A}_{0.05} \mathrm{~S}, \mathrm{~A}=\mathrm{Fe}\right.$ or $\left.\mathrm{Mn}\right)$ was prepared using the thermolysis technique. The effect of $\mathrm{Fe}$ and $\mathrm{Mn}$ doping on the lattice parameter, crystallite size, and lattice microstrain was examined applying Rietveld refinement. The analysis showed the incorporation of $\mathrm{Fe}$ and $\mathrm{Mn}$ substitutionally for $\mathrm{Zn}$ ions; a result confirmed by Fourier transforms infrared spectroscopy spectra from the shift in the vibration bands upon doping. The energy of $\mathrm{ZnS}$ band gap was reduced by doping, giving $\mathrm{ZnS}$ new applications. The different defects inside the different samples were investigated using photoluminescence spectroscopy. The effect of $\mathrm{Fe} / \mathrm{Mn}$ doping and incorporation of atmospheric oxygen on the bandgap characteristics, the absorption, optical conductivity, refractive index and the extinction coefficient, reflectance, the real and imaginary parts of the dielectric constant were explored using density function theory calculation (DFT).
\end{abstract}

Keywords: Nano ZnS; Mn, Fe doping; structure; optical properties; electronic properties.

*Corresponding Authors: Mohamed Bakr Mohamed (mbm1977@yahoo.com), Ali Badawi; daraghmeh@tu.edu.sa ). 


\section{Introduction}

Semiconductor materials with particular characteristics such as appropriate band gap and good adsorption in the visible range can be used in many applications [1]. $\mathrm{ZnS}(3.72-3.77 \mathrm{eV})$ is one of the wide-band-gap II-VI semiconductor materials that has been widely studied as an important phosphor material for promising optoelectronic and photonic applications [2]. As the crystallite size of the $\mathrm{ZnS}$ nanocrystal decreased below its Bohr excitonic radius, the band structure was changed, and all the optoelectronic characteristics were improved. ZnS has two common crystal structures: Hexagonal wurtzite and cubic zinc blend at room temperature [3]. Furthermore, the absorption edge of $\mathrm{ZnS}$ is shorter than $340 \mathrm{~nm}$, which permits only high-energy ultraviolet (UV) light absorption [3]. This light absorption edge can be redshifted upon doping the material with a suitable dopant element [3]. For example, as the semiconductor materials doped with transition metals such as $\mathrm{Ni}, \mathrm{Co}, \mathrm{Mn}, \mathrm{Fe} . .$. , the formed materials exhibited more exotic characteristics because of spin-spin exchange interactions [4-8]. For instants, doping ZnCdSe/ZnS core/shell quantum dots with Fe, the emission intensity was improved [9]. The energy band gap of nano $\mathrm{Zn}_{1 \text { - }}$ ${ }_{x} \mathrm{FexS}$ formed by aqueous synthesis derived was increased as the amount of Fe increased in the matrix due to Burstein-Moss filling effect [4, 10]. Also, the photoluminescence (PL) intensity of orange-red emission was improved by increase in the $\mathrm{Fe}^{3+}$ doped amount in the $\mathrm{ZnS}$ matrix [4]. On the other hand, the PL intensity in Fe-doped $\mathrm{ZnS}$ with wurtzite structure revealed a quenching behavior at a higher Fe-doping amount [11]. Wang et al. showed that the optical band gap of $\mathrm{ZnS}$ formed by one-pot hydrothermal procedure was decreased as it doped with Fe [3]. Yu et al. found that Fe:ZnSe transparent ceramics prepared by co-precipitation method and spark plasma sintering have a reddish-brown color and can act as a promising mid-infrared laser material [12]. Mahmood et al. found by applying the first-principle approach that the bandgap of $\mathrm{ZnS}$ can be tunable from ultraviolet to visible regions as it doped with iron doping [13]. The energy gap of nano $\mathrm{Zn}_{0.75} \mathrm{Cd}_{0.25} \mathrm{~S}$, was reduced upon doping with a small amount of $\mathrm{Fe}$, then it increased with further Fe doping [8]. Also, the emitted colors of Fe doped nano $\mathrm{Zn}_{0.75} \mathrm{Cd}_{0.25} \mathrm{~S}$ depended on the excitation wavelengths and the amount of Fe-doping [8]. Furthermore, $\mathrm{Zn}_{0.55} \mathrm{Fe}_{0.2} \mathrm{Cd}_{0.25} \mathrm{~S}$ showed weak ferromagnetic characteristics [8]. Scanning tunneling spectroscopy spectra revealed a decrease in the electronic band gap in both CdS and ZnS upon doping with Mn [14]. Mn:ZnS demonstrated a rigid band shift toward higher bias, which is reminiscent of a hole-doping effect while Mn:CdS exhibited no rigid band shift [14]. Barman et al. found that the optical bandgap of Mn-doped ZnS which was prepared at low temperature, revealed a blue shift as compared with the undoped sample and it emitted yellow/red colors [15]. The bandgaps of $\mathrm{Zn}_{1-\mathrm{x}} \mathrm{Mn}_{\mathrm{x}} \mathrm{S}$ nanowires exhibited a nonlinear bowing nature against the composition $(\mathrm{x})$ which is important for their better uses in photonics and spintronics [16]. On the other hand, the band gap of Mn-doped $\mathrm{ZnS}$ thin films formed by chemical bath deposition technique was increased as the amount of Mn increased in the matrix and the highest photoluminescent yield was detected in 6 at. \% Mn-doped sample [17]. Nguyen et al. studied the influence of precursor molar ratio and annealing temperature on the properties of $\mathrm{Mn}$ doped $\mathrm{ZnS}$ quantum dots, and they found that the $\mathrm{ZnS}: \mathrm{Mn}^{2+}$ QDs can be especially an appropriate member for biological uses, security ink applications, and electroluminescence devices [18]. Nishimura et al. found that the photoluminescent quantum yield (PL QY) of the ZnSe:Mn QDs synthesized under the optimum conditions reached $20 \%$, which is the highest value ever reported for a water soluble ZnSe:Mn core QD [19]. Furthermore, by introducing a ZnS shell at the surface of the ZnSe:Mn QDs (ZnSe:Mn/ZnS core/shell QDs), the PL QY was increased to 30\% [19]. In this work, the influence of 5\% Fe or Mn doping on the structure and optical behaviors of nano $\mathrm{ZnS}$ were investigated in detail by applying X-ray diffraction (XRD), transmission electron microscope 
(TEM), Fourier transforms infrared (FTIR), ultraviolet spectroscopy (UV/VIS) and photoluminescence (PL) techniques. In addition, the electronic performance of the undoped and doped samples was examined by applying Castep program relies on density function theory calculation (DFT).

\section{Methods and materials}

$5 \% \mathrm{Fe}$ and $\mathrm{Mn}$-doped nano $\mathrm{ZnS}\left(\mathrm{Zn}_{0.95} \mathrm{~A}_{0.05} \mathrm{~S}, \mathrm{~A}=\mathrm{Fe}\right.$ or $\left.\mathrm{Mn}\right)$ was prepared by thermolysis technique using zinc, manganese acetates, iron citrate and thiourea. The required amount of the different salts were mixed, ground and heated in an electric oven at $400{ }^{\circ} \mathrm{C}(2 \mathrm{~h})$. The X-ray diffraction patterns were measured by X'pert MPD Philips $\left(\mathrm{Cu}-\mathrm{K}_{\alpha}\right.$ source, $\mathrm{LaB}_{6}$ standard for instrumental broadening correction). Different structures and microstructure parameters were extracted using MAUD program which depended on Rietveld profile method [20, 21]. UV-vis spectroscopy (Shimadzu UV-3101PC UV-Vis-NIR scanning spectrometer) was used to determine the optical bandgap of the different samples. The emitted colors from different samples were found using photoluminescence (PL) technique (luminescence spectrophotometer (RF-1501 SHIMADZU, Ltd)). Fourier transforms infrared (FTIR) technique (Bruker Tensor 27 FTIR spectrometer) was used to determine the different vibration bands of the studied materials. The electronic structure's parameters were found using Cambridge sequential total energy package (CASTEP) code based on the first principle calculation [22]. The supercell with $2 \times 2 \times 1$ dimension was used during the calculation for undoped and doped ZnS. An ultra-soft pseudopotential, GGA-PBE and energy cutoff $(380 \mathrm{eV})$ was used in the calculations [23, 24]. In the case of a Fe or Mn-doped ZnS system, one ion of $\mathrm{Zn}$ was replaced by either Fe or Mn ion. The influence of oxygen ion on the electronic properties of undoped and doped $\mathrm{ZnS}$ with Fe or Mn ions was investigated by replacing one sulfur ion with an oxygen ion. The $3 d^{10} 4 s^{2}, 3 d^{6} 4 s^{2}, 3 d^{5} 4 s^{2}, 3 s^{2} 3 p^{4}$ and $2 s^{2} 2 p^{4}$ electrons related to $\mathrm{Zn}, \mathrm{Fe}$, $\mathrm{Mn}, \mathrm{S}$ and $\mathrm{O}$ atoms were used for the pseudopotential arrangements, respectively. The absorption coefficient $(\alpha(\omega))$, the refractive index (n), extinction coefficient $(\mathrm{k})$, the real and imaginary dielectric parts $\left(\varepsilon_{1}, \varepsilon_{2}\right)$ and the optical conductivity $(\sigma(\omega))$ were calculated using the KramersKronig relations $[25,26]$.

\section{Results and discussion}

\subsection{Structural analysis}

X-ray diffraction patterns, Fig. 1, resembled single phase zinc blende cubic structure for all samples. No other phases were found implying the incorporation of Fe and $\mathrm{Mn}$ into the $\mathrm{ZnS}$ lattice, substitutionally for $\mathrm{Zn}$ ions. The effect of $\mathrm{Fe}$ and $\mathrm{Mn}$ doping on the lattice parameter, crystallite size, and lattice microstrain was examined applying Rietveld refinement and the resulting refined parameters are given in table 1 . The lattice parameter increased slightly due to the small doping percentage $5 \%$; the increase may be ascribed to the difference between the ionic radii for tetrahedral coordination $\mathrm{Zn}^{2+}=0.6, \mathrm{Fe}^{2+}=0.63$, and $\mathrm{Mn}^{2+}=0.66 \mathrm{pm}$ [27]. The crystallite size and lattice strain are almost isotropic and did not change significantly upon doping. The obtained Fe and $\mathrm{Mn}$ occupancies, table 1 , are very close to the intended doping value, confirming the incorporation substitutionally for $\mathrm{Zn}$ ions. Fig.2 shows the Fourier transforms infrared spectroscopy spectra (FTIR) for undoped and doped $\mathrm{ZnS}$ doped with $\mathrm{Fe}$ and $\mathrm{Mn}$ at room temperature in the range of $400-1200 \mathrm{~cm}^{-1}$. The figure revealed that all samples have similar features, but the intensity and wavenumber of different vibration bands affected by the kind of the 
doped element. The vibration bands observed at 400-418 $\mathrm{cm}^{-1}, 612-620 \mathrm{~cm}^{-1}$, and $1020-1150$ $\mathrm{cm}^{-1}$ are the characteristic bands of $\mathrm{ZnS}$; asymmetric bending, symmetric bending, and asymmetric stretching respectively [28]. It is important to notice the little shift in the wavenumber of bands upon doping, a behavior confirming the incorporation of Fe and Mn substitutionally for $\mathrm{Zn}$ ions. The vibration bands of C-S linkage and S-O-C are observed in the range at 701-598 and $1023 \mathrm{~cm}^{-1}$, respectively [29].

\subsection{UV absorption analysis}

To determine the direct energy gap $\left(\mathrm{E}_{\mathrm{g}}\right)$ of undoped and doped nano $\mathrm{ZnS}$ with $\mathrm{Fe}$ and $\mathrm{Mn}$, the following Tauc's relation [30] was applied:

$$
\begin{aligned}
& (\alpha h v)^{2}=D\left(h v-E_{g}\right) \\
& \alpha=\frac{2.303 A}{t}
\end{aligned}
$$

where D, A and t are a constant, absorbance and thickness of the sample, respectively.

Fig. 4 reveals the graphic relation between $(\alpha h v)^{2}$ and hv and from the plot $E_{g}$ value can be extracted by extrapolating the straight-line portion of the graph on the ho axis. The obtained $\mathrm{E}_{\mathrm{g}}$ values for $\mathrm{ZnS}$ and $\mathrm{ZnS}$ doped samples with Fe or $\mathrm{Mn}$ are 3.26, 2.83 and $3.12 \mathrm{eV}$, respectively. The obtained $\mathrm{E}_{\mathrm{g}}$ for $\mathrm{ZnS}$ samples is compatible with other literature values [31] and less than other $\mathrm{ZnS}$ prepared with different methods [32,33]. It is known the energy gap affected by the size of the sample and the process of formation: for example, $\mathrm{ZnS}$ formed using different chemical methods exhibited energy gap values of 3.5, 4.79 and $3.95 \mathrm{eV}$, which are corresponding to the crystallite size of 4.9, 6.73 and $4.8 \mathrm{~nm}$, respectively [31-33]. Furthermore, the energy gaps of doped materials are less than the undoped ones. Cai et al. found as the amount of Mn-doped $\mathrm{ZnS}$ nanowires increased up to $6 \%$, the energy gap of $\mathrm{ZnS}$ decreased, and by further doping, the energy gap increased [16]. The optical band gap of Mn-doped $\mathrm{ZnS}$ nanoparticles synthesized at $95{ }^{\circ} \mathrm{C}$ in basic aqueous solution using the nucleation-doping strategy was reduced as the amount of $\mathrm{Mn}$ doping increased in the matrix [34]. Poornaprakash et al. found a similar result as $\mathrm{ZnS}$ doped with $\mathrm{Mn}$, where the optical band gap of $\mathrm{ZnS}$ was reduced as it was doped with $\mathrm{Mn}$, due to sp- $\mathrm{d}$ spin exchange interaction between the band and localized electrons of the transition metal ion substituting the cation [35]. Vineeshkumar et al. found the energy gap of $\mathrm{ZnS}$ formed by polyethylene glycol assisted hydrothermal procedure was decreased as it doped with Fe [36]. The optical band gaps of $\mathrm{Fe}_{\mathrm{x}} \mathrm{ZnS}$ catalysts synthesized by a one-pot hydrothermal process were apparently less than the band gap of $\mathrm{ZnS}$, indicating that Fe doping effectively reduced the bandgap of $\mathrm{ZnS}$ catalyst [3]. The reduction in bandgap of $\mathrm{ZnS}$ as it doped with Fe can be explained also as the possibility of the present of a small amount of FeS phase which has a smaller bandgap (1.1 eV) as compared with $\mathrm{ZnS}$ sample [37], which is not detected from XRD analysis in our case. Conversely, Padmavathi et al. demonstrated that Fe or Mn-doped ZnS exhibited a redshift using spin- polarized first principles calculations method and applying mBJ approximation [38].

\subsection{Photoluminescence analysis}

Fig. 4 shows the Gaussian fitting of photoluminescence (PL) spectra at an excitation wavelength of $350 \mathrm{~nm}$ for $\mathrm{ZnS}$ and $\mathrm{Zn}_{0.95} \mathrm{X}_{0.05} \mathrm{~S}$ (X= Fe, Mn) samples. It is observed from the figure that the $\mathrm{PL}$ intensity of $\mathrm{ZnS}$ was reduced as $\mathrm{ZnS}$ doped with either Fe or Mn. Peppers et al., revealed that 
the excitonic emission of ZnSe crystal is quenched as it doped with Fe ions [39]. On contrary, the PL intensity of Fe-doped ZnS nanorods was increased as the amount of Fe concentration increased in $\mathrm{ZnS}$ [11]. The reduction in PL intensity as Fe or Mn-doped ZnS matrix in our case is due to the plying of Fe or Mn ions as quenching centers of fluorescence; Fe or Mn acts as an electron trapping center which out from non-radiative recombination [40]. Furthermore, $\mathrm{ZnS}, \mathrm{Fe}$-doped $\mathrm{ZnS}$ and Mn-doped ZnS emitted (violet, three blues), (violet, two blues) and (violet, blue, green) colors. Nano ZnS formed using aqueous synthesis method emitted violet and blue colors [4]. Fe-doped $\mathrm{ZnS}$ nanorods emitted blue and green emissions [11]. Nano Fe-doped ZnS formed by a refluxing procedure emitted a blue color only and its intensity was reduced as the Fe doped amount increased in the matrix [35]. On the other hand, Fe-doped Nano wurtzite $\mathrm{ZnS}$ emitted blue and red colors as it doped with Fe [41]. Fe-doped Nano ZnS prepared by a microwave-assisted co-precipitation process revealed UV, violet and orange colors as it doped with Fe [39]. Fe-doped nano $\mathrm{ZnS}$ formed using aqueous synthesis method emitted violet, blue, green, orange and red colors [4]. $\mathrm{Zn}_{1 \text { - }}$ ${ }_{x} \mathrm{Fe}_{\mathrm{x}} \mathrm{S}$ nanospheres emitted green and yellow colors [36]. Mn-doped $\mathrm{ZnS}$ quantum dots prepared by hydrothermal procedure revealed blue and green colors [42]. The violet color may be caused by anion $\left(\mathrm{S}^{2-}\right)$ vacancy $\left(\mathrm{V}_{\mathrm{s}}\right)$ which acts as a common electron trap under the conduction band edge, hole traps like cation vacancies $\left(\mathrm{V}_{\mathrm{Zn}}\right)$ and surface states $(\mathrm{SS})$, which are in lower energy states [43]. The blue color caused by the transition from $V_{s}$ to $V_{Z n}$ [43]. The observed green luminescence emission owes to increase in the lattice defects [44].

\subsection{Electronic structure properties analysis}

Since the undoped and doped $\mathrm{ZnS}$ samples were prepared in air, therefore maybe there is some oxygen enter the lattice. The electronic characteristics of undoped and doped $\mathrm{ZnS}$ with Fe or Mn (where one atom of $\mathrm{Zn}$ is replaced by a either Fe or $\mathrm{Mn}$ atom, $\mathrm{ZnS} /(\mathrm{Fe}, \mathrm{Mn})$ ) and undoped and doped $\mathrm{ZnS}$ with (Fe or $\mathrm{Mn}$ ) and oxygen (where one atom of $\mathrm{Zn}$ is substituted by $\mathrm{Fe}$ or $\mathrm{Mn}$ atom and one sulfur atom is substituted by one oxygen atom $=\mathrm{ZnS} / \mathrm{O}$ and $\mathrm{ZnS} /(\mathrm{Fe}$ or $\mathrm{Mn}, \mathrm{O})$ ) was investigated using a unit cell with the zinc-blende unit cell with space group F-43m as an initial model. The lattice parameters obtained from XRD diffraction were used as preliminary values for the DFT calculation. After the geometry relaxation, the obtained lattice parameters are 5.4015, 5.3494, 5.4089, 5.3902, 5.4175 and 5.4093 Å for ZnS, Zn/O, ZnS/Fe, ZnS/(Fe, O), ZnS/Mn and $\mathrm{ZnS} /(\mathrm{Mn}, \mathrm{O})$, respectively. The lattice parameter of the $\mathrm{ZnS} /(\mathrm{Fe}$ or $\mathrm{Mn})$ sample is slightly larger than that of the $\mathrm{ZnS}$ sample, as a result of replacing the smaller ionic radius ion (Zn) with a bigger ionic radius ion (Fe or $\mathrm{Mn}$ ) which is in consistence with XRD result. In contrast, the lattice parameter of $\mathrm{ZnS} / \mathrm{O}$ and $\mathrm{ZnS} /(\mathrm{Fe}$ or $\mathrm{Mn}, \mathrm{O})$ is smaller than the lattice parameter of other samples as a result of replacing of larger ionic radius ion (sulfur) with smaller ionic radius ion (oxygen). Figs.5, 6 show the spin-polarized band structures for $\mathrm{ZnS}, \mathrm{ZnS} / \mathrm{O}, \mathrm{ZnS} / \mathrm{Fe}, \mathrm{ZnS}(\mathrm{Fe}, \mathrm{O}), \mathrm{ZnS} / \mathrm{Mn}$ and $\mathrm{ZnS} /(\mathrm{Mn}, \mathrm{O})$ samples along the high symmetry direction of the first Brillouin zone. The Fermi energy level was located at zero energy. All undoped and doped $\mathrm{ZnS}$ samples exhibited a direct band semiconductor characteristic. The calculated energy gap for $\mathrm{ZnS}$ sample is $2.148 \mathrm{eV}$ which is smaller than the optical band gap obtained from the UV result [45]. The small value of the calculated bandgap is underestimated because of the accepted limitation of expecting the precise energy band properties [46]. The bandgap of $\mathrm{ZnS}$ was decreased as it doped with $\mathrm{Fe}$ and/or O, reached $1.853 \mathrm{eV}$, and both samples exhibited a half-metallic characteristic. On the other hand, $\mathrm{Mn}$ and/or $\mathrm{O}$ doped $\mathrm{ZnS}$ revealed a semiconductor nature and the band gap decreased in both samples as compared with the undoped $\mathrm{ZnS}$ sample. A similar effect was achieved by Padmavathi et al. using a Full Potential Linearized Augmented Plane Wave (FP-LAPW) method [38]. Fig.7a,b 
show the optical absorption for $\mathrm{ZnS}, \mathrm{ZnS} / \mathrm{O}, \mathrm{ZnS} / \mathrm{Fe}, \mathrm{ZnS} /(\mathrm{Fe}, \mathrm{O}), \mathrm{ZnS} / \mathrm{Mn}$ and $\mathrm{ZnS} /(\mathrm{Mn}, \mathrm{O})$ samples as a function of the photon energy. The absorption spectra for all samples exhibited two peaks which were shifted to higher energy values upon doping with $\mathrm{Fe}$ or $\mathrm{Mn}$ or/and $\mathrm{O}$. In the visible region $\mathrm{ZnS} / \mathrm{O}$ has better absorption than $\mathrm{ZnS}$, while in the $\mathrm{UV}$ region the situation is reversed. In addition, the absorption was enhanced in the visible region while it reduced in the UV region as $\mathrm{ZnS}$ doped with Fe or Mn and/or oxygen. As revealed in Fig.7c, Fe-doped $\mathrm{ZnS}$ revealed a higher absorption than Mn-doped ZnS sample. Figs. 8a, b reveal the optical conductivity $(\sigma(\omega))$ of $\mathrm{ZnS}, \mathrm{ZnS} / \mathrm{O}, \mathrm{ZnS} / \mathrm{Fe}, \mathrm{ZnS} /(\mathrm{Fe}, \mathrm{O}), \mathrm{ZnS} / \mathrm{Mn}$ and $\mathrm{ZnS} /(\mathrm{Mn}, \mathrm{O})$ samples. As demonstrated from the figure, the optical conductivity of all samples has two peaks. The intensity of the main peak decreased when Fe or Mn and/or O doped $\mathrm{ZnS}$, whereas the small peak in the UV affected a little with doping. The peaks occurred in the UV region caused by the interband transitions [47]. The reduction in the main peak in the case of $\mathrm{Mn}$-doped $\mathrm{ZnS}$ is larger than Fe doped $\mathrm{ZnS}$ sample, Fig.8c. Besides, the optical conductivity in the visible range enhanced slightly with doping. The photon energy dependence of the refractive index (n) and the extinction coefficient (k) are demonstrated in Fig.9, where the refractive index was enhanced until reached its highest value at a specific energy range then it decreased with increased photon energy, Figs.9a-c. A small peak has emerged at a higher energy range for all samples. The variation that takes place in the refractive index characteristics may be caused by the dispersion of the light inside the material. Accordingly, many interactions can happen with the different atoms inside the unit cell. The refractive index has high values in the low energy region and its highest value (around $4 \mathrm{eV}$ ) reduced as $\mathrm{ZnS}$ doped with $\mathrm{Fe}$ or $\mathrm{Mn}$ and/or O. The extinction coefficient values of all samples revealed as steadily rising as the photon energy value increased until reached the highest value then it reduced with further increased in the photon energy, Figs.9d-f. Also, a small hump occurred in the high energy region for all samples. The extinction coefficient was improved in the visible region as $\mathrm{ZnS}$ doped with $\mathrm{Fe}$ or $\mathrm{Mn}$ and/or $\mathrm{O}$. The extinction coefficient in the visible region in the case of Fe doped is higher than the Mn-doped $\mathrm{ZnS}$ sample. The intensity of the maximum peak was decreased as $\mathrm{ZnS}$ doped with $\mathrm{Fe}$ or $\mathrm{Mn}$ and/or $\mathrm{O}$ because of the atomic correlation and interactions. The reduction in the highest peak is occurred further in Mn-doped $\mathrm{ZnS}$ as compared with Fe doped one.

Fig.10 shows the real and imaginary parts of the dielectric constant as a function of the photon energy for all samples, which demonstrated roughly alike tendency. Additionally, the dielectric constant has negative values in a specific energy range for all samples, established that the materials have a metallic performance in this range [47]. The negative dielectric value was reduced as $\mathrm{ZnS}$ sample doped with Fe or $\mathrm{Mn}$ and/or O. Additionally, $\mathrm{ZnS}$ doped with Fe or $\mathrm{Mn}$ and $\mathrm{O}$ samples have the highest static dielectric constant among the other undoped and doped samples, sample with Fe and $\mathrm{O}$ higher than with $\mathrm{Mn}$ and $\mathrm{O}$. The imaginary part of the dielectric constant has two peaks. The higher one is shifted to the high energy region as $\mathrm{ZnS}$ doped with Fe or $\mathrm{Mn}$ and/or O comparing with undoped one. In energy-loss graph, Fig.11, the maximum peak position, known as the bulk plasma frequency $\left(\omega_{\mathrm{p}}\right)$, was shifted to a lower energy value as ZnS doped with $\mathrm{Fe}$ or $\mathrm{Mn}$ and/or $\mathrm{O} ; \omega_{\mathrm{p}}$ occurs when $\varepsilon_{2}$ less than 1 and $\varepsilon_{1}$ nearly became zero $[48,49]$. Additionally, the intensity of $\omega_{\mathrm{p}}$ was reduced as $\mathrm{ZnS}$ doped Fe or $\mathrm{Mn}$ and/or O which indicated a fast reduction of the reflectance, Figs. 11d-f.

\section{Conclusion}

$\mathrm{Fe}$ and Mn-doped were obtained as single cubic phase applying thermolysis technique. Applying Rietveld analysis, the lattice parameter increased slightly, and the crystallite size and lattice strain are almost isotropic and did not change significantly upon doping. FTIR spectra confirmed the 
incorporation of Fe and $\mathrm{Mn}$ substitutionally for $\mathrm{Zn}$ ions. The energy gap for $\mathrm{ZnS}$ and $\mathrm{ZnS}$ doped samples with Fe and $\mathrm{Mn}$ are 3.26, 2.83 and $3.12 \mathrm{eV}$, respectively. The reduction of band gap upon doping is due to the $\mathrm{sp}-\mathrm{d}$ spin-exchange interaction between the band electrons and the localized electrons of the transition metal ion substituting the cation. The photoluminescence (PL) was reduced upon $\mathrm{Fe}$ and $\mathrm{Mn}$ doping. The emitted colors are violet, three blues for $\mathrm{ZnS}$, violet, two blues for Fe-doped $\mathrm{ZnS}$ and violet, blue, green for Mn-doped $\mathrm{ZnS}$. DFT calculations demonstrated that $\mathrm{ZnS}, \mathrm{Zn} / \mathrm{O}, \mathrm{ZnS} / \mathrm{Fe}, \mathrm{ZnS} /(\mathrm{Fe}, \mathrm{O}), \mathrm{ZnS} / \mathrm{Mn}$ and $\mathrm{ZnS} /(\mathrm{Mn}, \mathrm{O})$ samples exhibited a direct band semiconductor characteristic. Fe and/or $\mathrm{O}$ doped $\mathrm{ZnS}$ samples exhibited a half-metallic characteristic. The absorption enhanced in visible region while it reduced in UV region as $\mathrm{ZnS}$ doped with $\mathrm{Fe}$ or $\mathrm{Mn}$ and/or oxygen. Fe-doped $\mathrm{ZnS}$ revealed a higher absorption than the Mndoped $\mathrm{ZnS}$ sample. The optical conductivity in the visible range enhanced slightly with doping. The refractive index has high values in the low energy region and its highest value (around $4 \mathrm{eV}$ ) reduced as $\mathrm{ZnS}$ doped with Fe or $\mathrm{Mn}$ and/or O. $\mathrm{ZnS}$ doped with Fe or Mn and $\mathrm{O}$ samples have the highest static dielectric constant among the other undoped and doped samples, sample with Fe and $\mathrm{O}$ higher than with $\mathrm{Mn}$ and $\mathrm{O}$. The peak intensity of the bulk plasma frequency $\left(\omega_{\mathrm{p}}\right)$ reduced upon doping with $\mathrm{Fe}$ or $\mathrm{Mn}$ and/or $\mathrm{O}$ indicated a fast reduction of the reflectance.

\section{Acknowledgement}

The Authors thank the support of Taif University Researchers Supporting Project number (TURSP-2020/12), Taif University, Taif, Saudi Arabia.

\section{References}

[1] H. Zhou, Y. Qu, T. Zeid, X. Duan, Energy Environ. Sci. 5 (2012)6732.

[2] O. Baytar, O. Sahin, H. Kilicvuran, S. Horoz, J Mater Sci: Mater Electron 29 (2018) 4564.

[3] Q. Wang, P. Xu, G. Zhang, W. Zhang, L. Hu and P. Wang, Phys. Chem. Chem. Phys., 20 (2018) 18601.

[4] S. Ghorai, N. Patra, A. Pal, D. Bhattacharyya, S. N. Jha, B. Ray, S. Chatterjee, A. K. Ghosh, Journal of Alloys and Compounds 805 (2019) 363.

[5] Z.K. Heiba, M.B. Mohamed, S.I. Ahmed, A.A. Albassam, Journal of Materials Science: Materials in Electronics 31 (16) (2020) 13447.

[6] Z.K. Heiba, M.B. Mohamed, J.R. Plaisier, A.M. El-naggar, A.A. Albassam, 67(2020)414.

[7] Z.K. Heiba, M.B. Mohamed, Journal of Inorganic and Organometallic Polymers and Materials 30 (3) (2020)879.

[8] Z.K. Heiba, M.B. Mohamed, A.M. El-naggar, A.A. Albassam, 31, (2020) 21342.

[9] E. Soheyli, R. Sahraei, G. Nabiyouni, Journal of Luminescence 205(2019)352 .

[10] E. Burstein, Phys. Rev. 93 (1954) 632.

[11] S. Kumar, N. K. Verma, Journal of Elec Materi 44 (2015) 2829.

[12] S. Yu, D. Carloni, Y. Wu, J Am Ceram Soc. 103 (2020)4159.

[13] Q. Mahmood, M. Hassan, N. A. Noor, J Supercond Nov Magn 30 (2017)1463.

[14] A. J. Yost, T. K. Ekanayaka, G. Gurung, G. Rimal, S. Horoz, J. Tang, T. Paudel, T.Y.Chien, J. Phys. Chem. C 123 (2019)24890.

[15] B. Barman, K. C. Sarma, Solid State Sciences 109 (2020) 106404

[16] J. Cai, S. Wang, K. Zhu, Y. Wu, L. Zhou, Y. Zhang, Q. Wu, X. Wang, Z. Hub, RSC Adv. 8 (2018) 374.

[17] P. Babua, Minnam. Reddy, V. Reddy, S. Kondaiah, Kotte, T. R. Reddy, P.Chinho, Optik, 130(2017) 608.

[18] T. P. Nguyen, Q. V. Lam, T. B. Vu, Journal of Luminescence 196 (2018) 359. 
[19] H.Nishimura, Y. Lin, M. Hizume, T. Taniguchi, N. Shigekawa, T. Takagi, S. Sobue, S. Kawai, E. Okuno, D. Kim, AIP Advances 9 (2019) 025223

[20] L. Lutterotti, Nucl. Inst. Methods, Phys. Res. B. 268 (2010)334.

[21] J. Rodríguez-Carvajal, Phys. B (Amsterdam, Neth.) 192 (1993) 55.

[22] J.P. Perdew, K. Burke, M. Ernzerhof, Phys.Rev. Lett 77 (1996) 3865.

[23] J.P. Perdew, Y. Wang, Phys. Rev. B 45 (1992)13244.

[24] ZK Heiba, AA Albassam, MB Mohamed, Applied Physics A 126 (2020) 479.

[25] H. Ehrenreich and M.L. Cohen, Phys. Rev. 115 (1959)786.

[26] F. Wooten, Optical Properties of Solids (New York: Academic, 1972).

[27] R.D. Shannon, Acta Crystallogr. A 32 (1976)75.

[28] Zein K. Heiba, Mohamed Bakr Mohamed, S. I. Ahmed, A. A. Albassam, Journal of Materials Science: Materials in lectronics volume 31 (2020)13447.

[29] M. Kuppayee, G.K.V. Nachiyar, V. Ramasamy, Mater. Sci. Semicond. Process. 15 (2012) 136.

[30] J. Tauc, in: A. Abeles (Ed.), The Optical Properties of Solid, 1972, p. 277. North Holland, Amsterdam.

[31] Y. Hu, B. Hu, B. Wu, Z. Wei, J. Li. J. Mater. Sci.- Mater. Electron. 29(19) (2018) 16715.

[32] J. K. Salem, T. M. Hammad, S. Kuhn, M. A. Draaz, N. K. Hejazy, R. Hempelmann, Journal J. Mater. Sci.- Mater. Electron. 25 (2014) 2177.

[33] K. Patel, M. Deshpande, S. Chaki, J. Mater. Sci.- Mater. Electron. 28(6) (2017)5029.

[34] H.Labiadh, B.Sellami, A.Khazri, W.Saidani, S.Khemais, Optical Materials, 64(2017)179.

[35] B. Poornaprakash, D. A. Reddy, G. Murali, R. P. Vijayalakshmi, B. K. Reddy, Physica E $73(2015) 63$.

[36]T.V.Vineeshkumar, R. Raj, S.Prasanth, N.V.Unnikrishnan, V.P.M. Pillai, C. Sudarasanakumara, Optics \& Laser Technology, 99(2018) 220.

[37] P. C. Patel, P. C. Srivastava, J. Mater. Sci.- Mater. Electron. 49 (17) (2014) 6012.

[38] S.Padmavathi, R.John, Materials Science and Engineering: B, 248(2019) 114401.

[39] J. Peppers, V.V. Fedorov, S.B. Mirov, Opt. Express 23 (2015) 4406.

[40] X.J. Wu, D.Z. Shen, Z.Z. Zhang, J.Y. Zhang, K.W. Liu, Appl. Phys. Lett. 89 (2006) 262118.

[41] B. Poornaprakash, D. Amaranatha Reddy, G. Murali, N. Madhusudhana Rao, R. P. Vijayalakshmi, B.K. Reddy, J. Alloy. Compd. 577 (2013) 79.

[42] Y. Hu, B. Hu, B. Wu, Z. Wei, J. Li. J. Mater. Sci.- Mater. Electron. 29(19) (2018) 16715.

[43] N. Eryong, L. Donglai, Z. Yunsen, B. Xue, Y. Liang, J. Yong, J. Zhifeng, S. Xiaosong, Appl. Surf. Sci.257 (2011)8762.

[44] S.Cao, H.Wang, H. Li, J. Chen, Z. Zang, Chemical Engineering Journal 394 (2020) 124903. [45] Z.K. Heiba, M.B. Mohamed, A.M. El-naggar, AA Albassam, J Mater Sci: Mater Electron 31(2020) 21342.

[46] ZK Heiba, MB Mohamed, AM Wahba, J Mater Sci: Mater Electron 31(2020) 14645.

[47] M. Hassan, N.A. Noor, Q. Mahmood, B. Amin, Current Applied Physics 16(11) (2016) 1473.

[48] A. Bouhemadou, R. Khenata, Comput. Mater. Sci. 39 (2007) 803.

[49] C. Li, B. Wang, R. Wang, H. Wang, X. Lu, Comput. Mater. Sci. 42 (4) (2008) 614. 

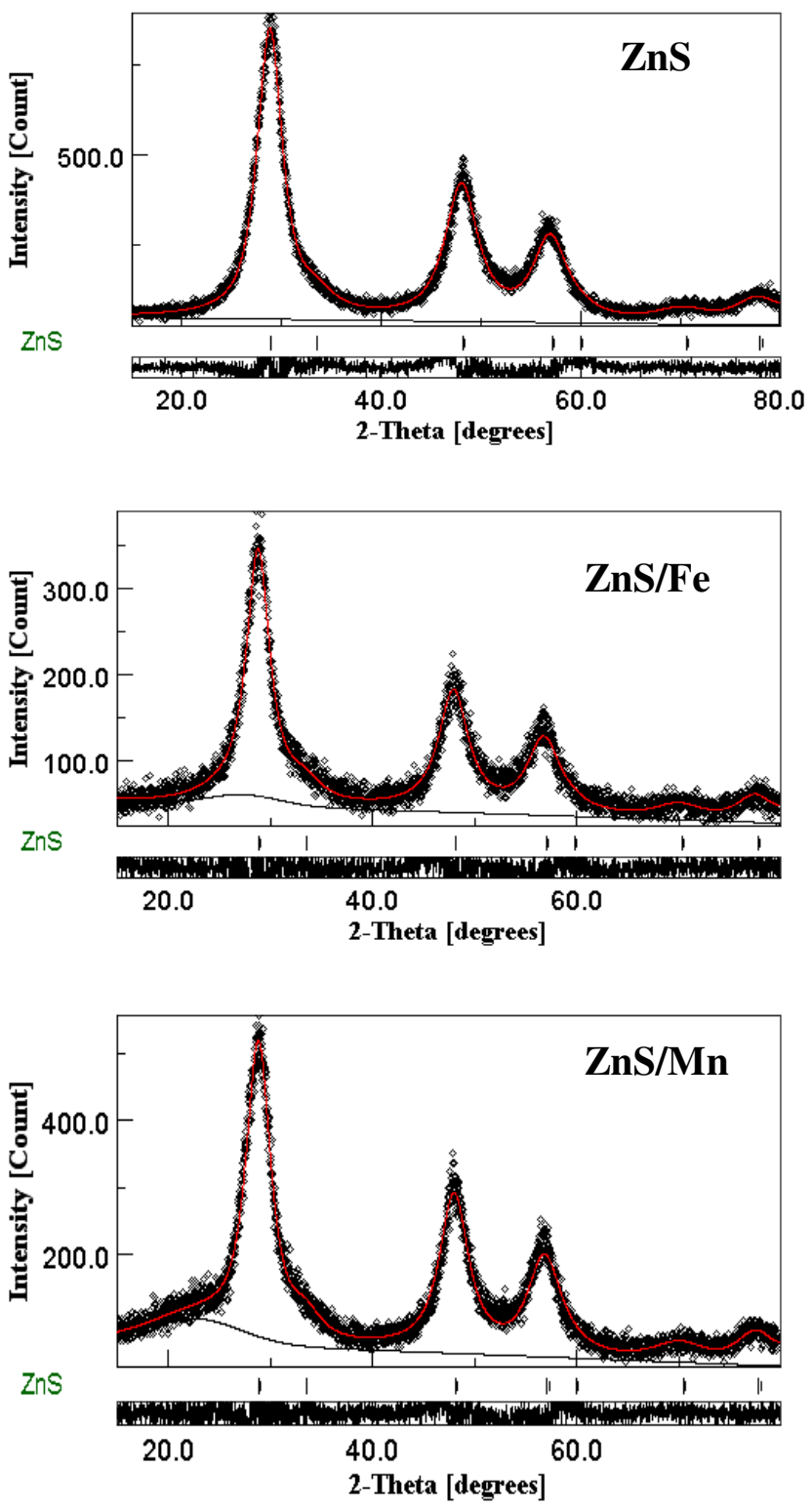

Fig.1. Rietveld refinement for undoped and $\mathrm{Fe}$ or $\mathrm{Mn}$ doped nano $\mathrm{ZnS}$. 


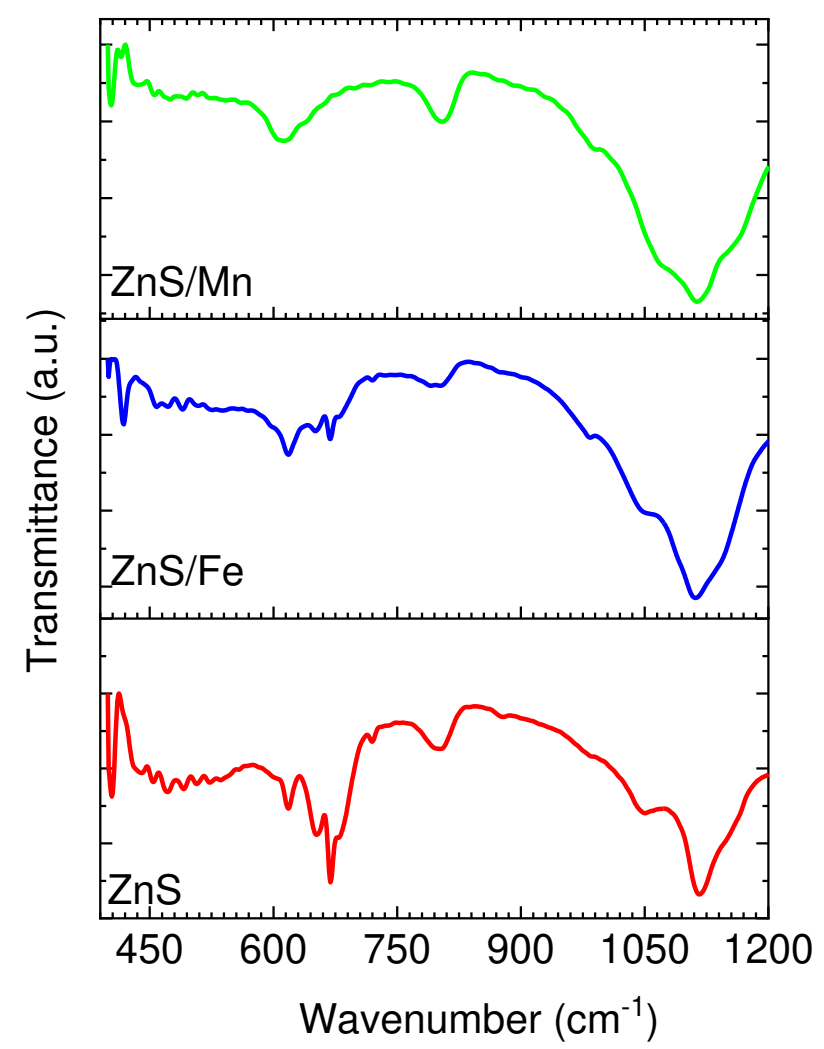

Fig.2. FTIR spectra for undoped and Fe and Mn-doped nano ZnS. 


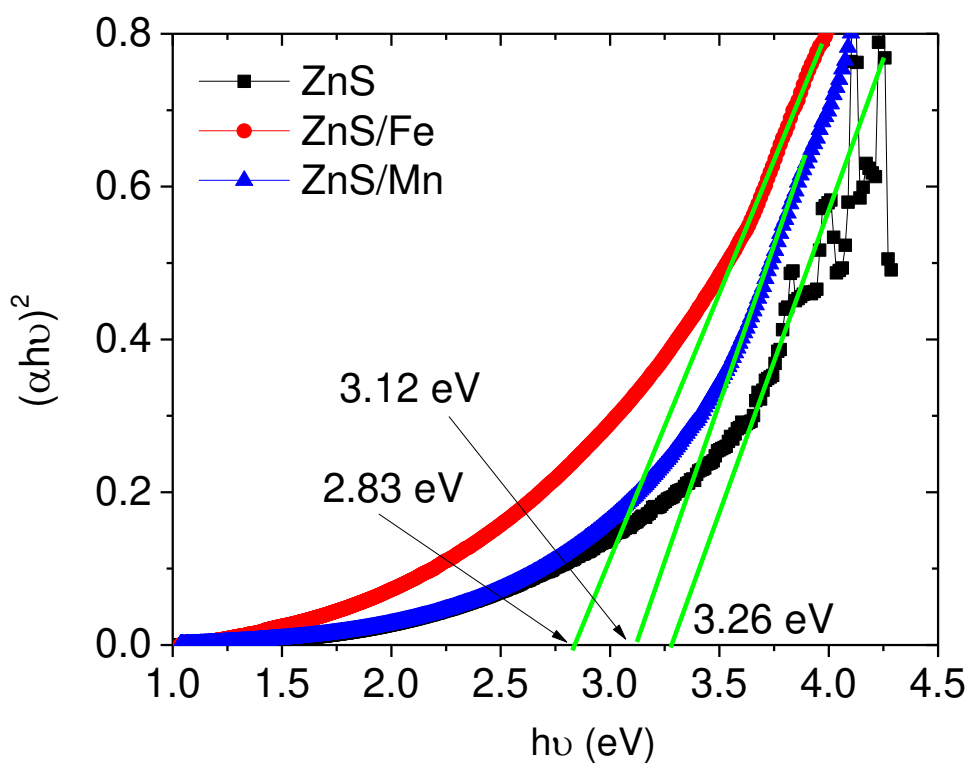

Fig.3. Plots of $\left((\alpha h v)^{2}\right)$ vs photon energy (hv) for undoped and Fe or Mn-doped nano $\mathrm{ZnS}$. 

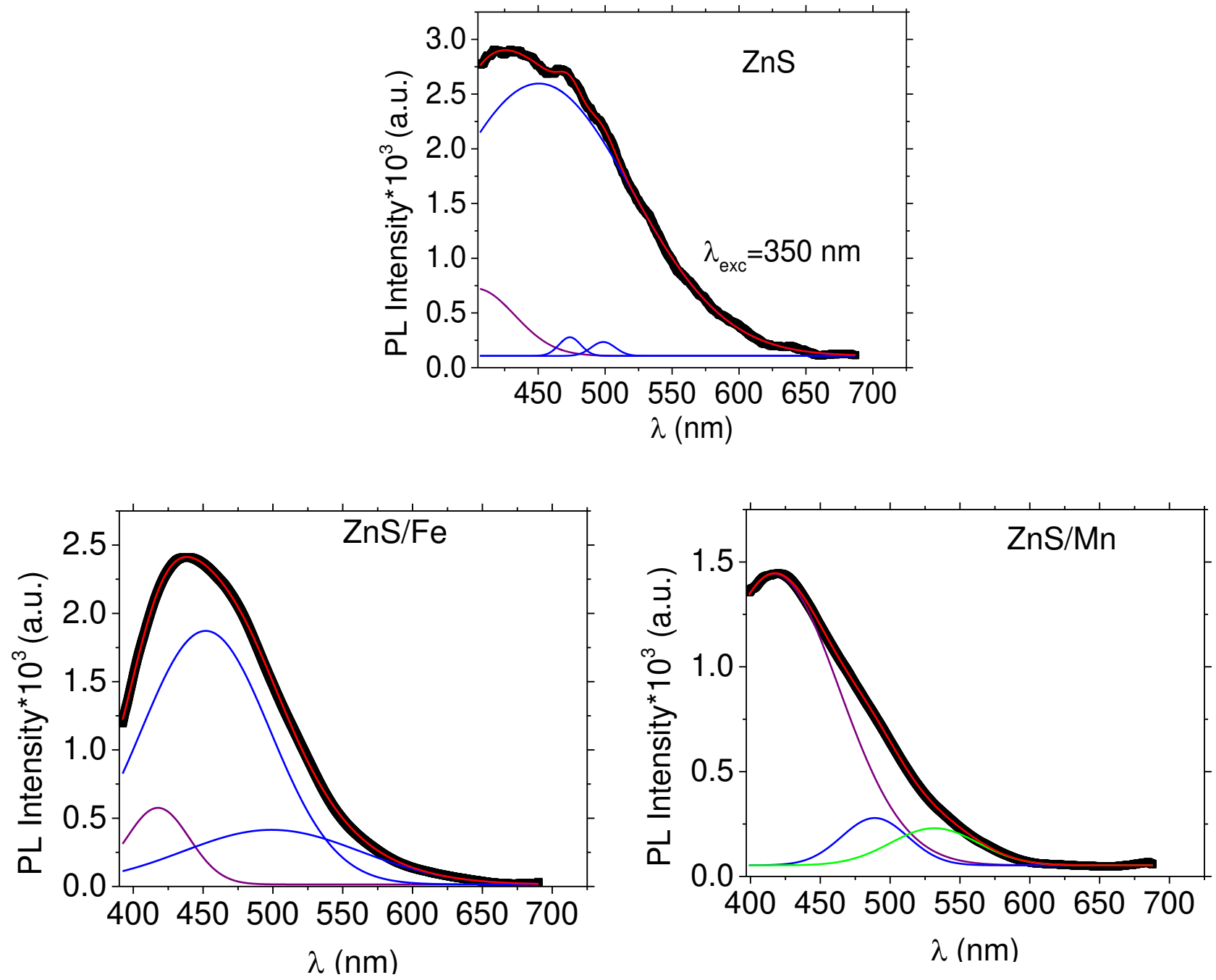

Fig.4. Gaussian fitting for photoluminescence (PL) spectra vs wavelength $(\lambda)$ for undoped and Fe or Mn-doped nano ZnS. 

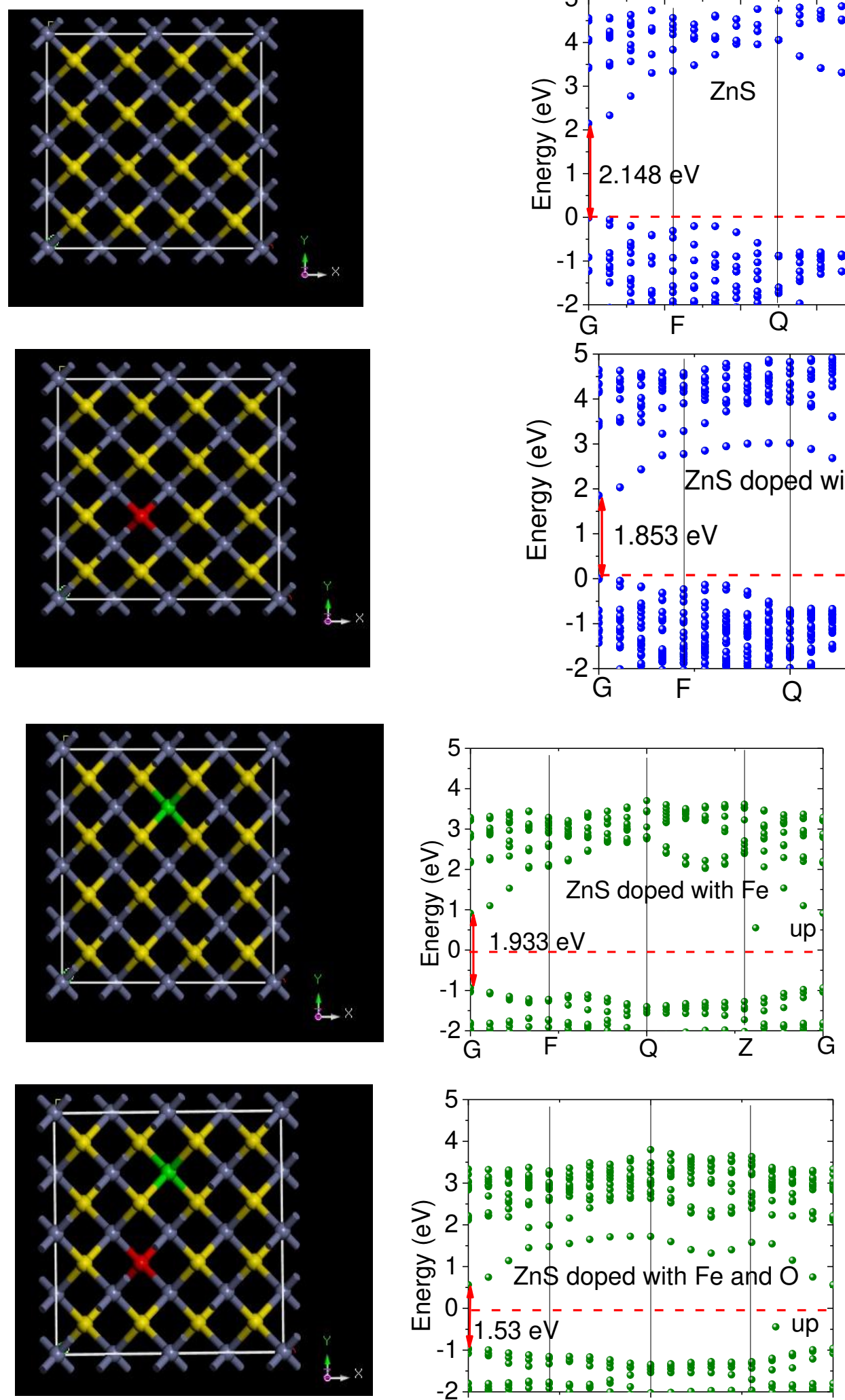
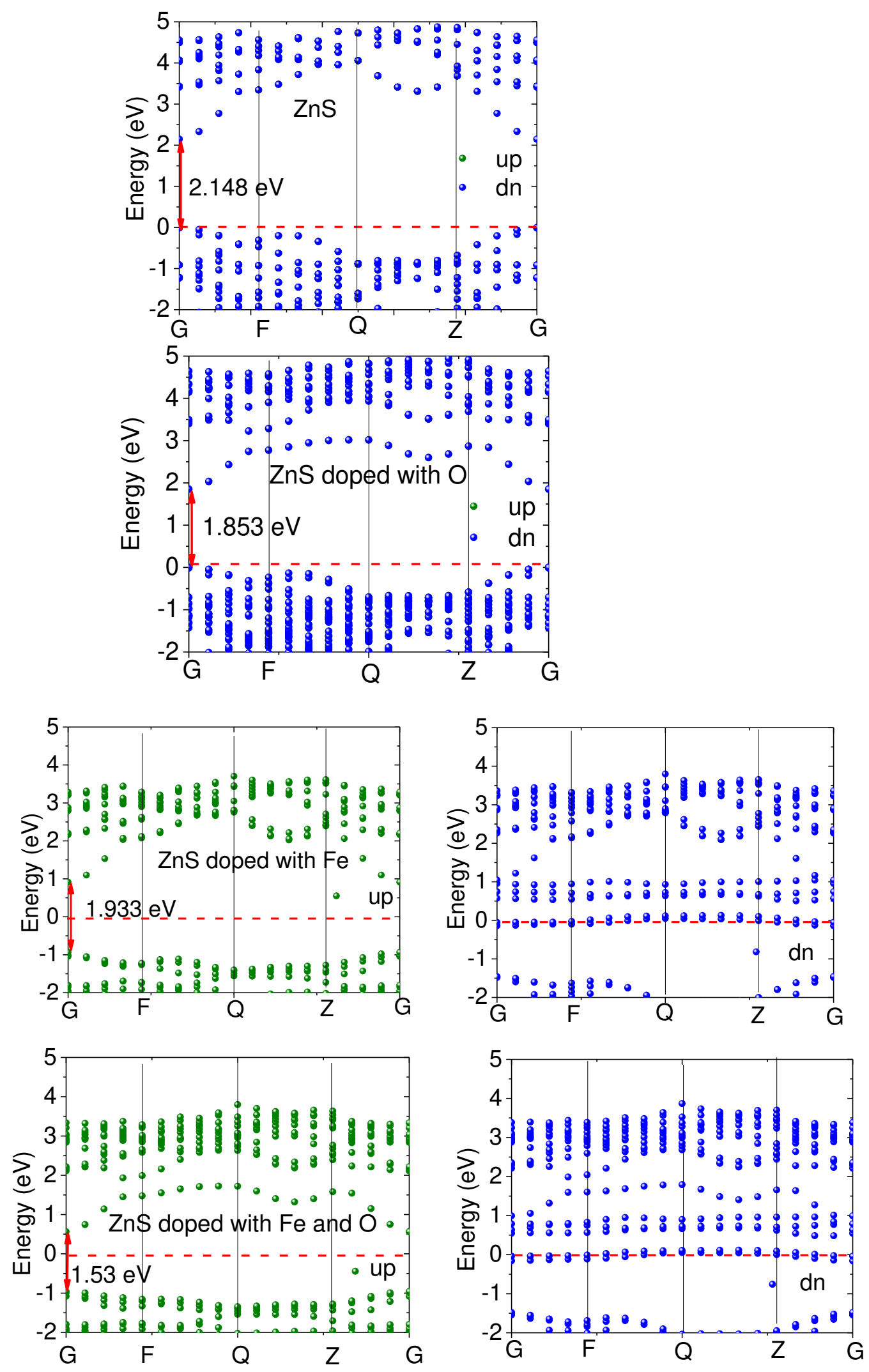
Fig.5. (a) supercells used in the calculation, yellow (red) and violet (green) balls indicate $\mathrm{S}(\mathrm{O}), \mathrm{Zn}(\mathrm{Fe}$ or $\mathrm{Mn})$ and (b) the spin-polarized band structures (up and down) for undoped and Fe-doped nano ZnS.
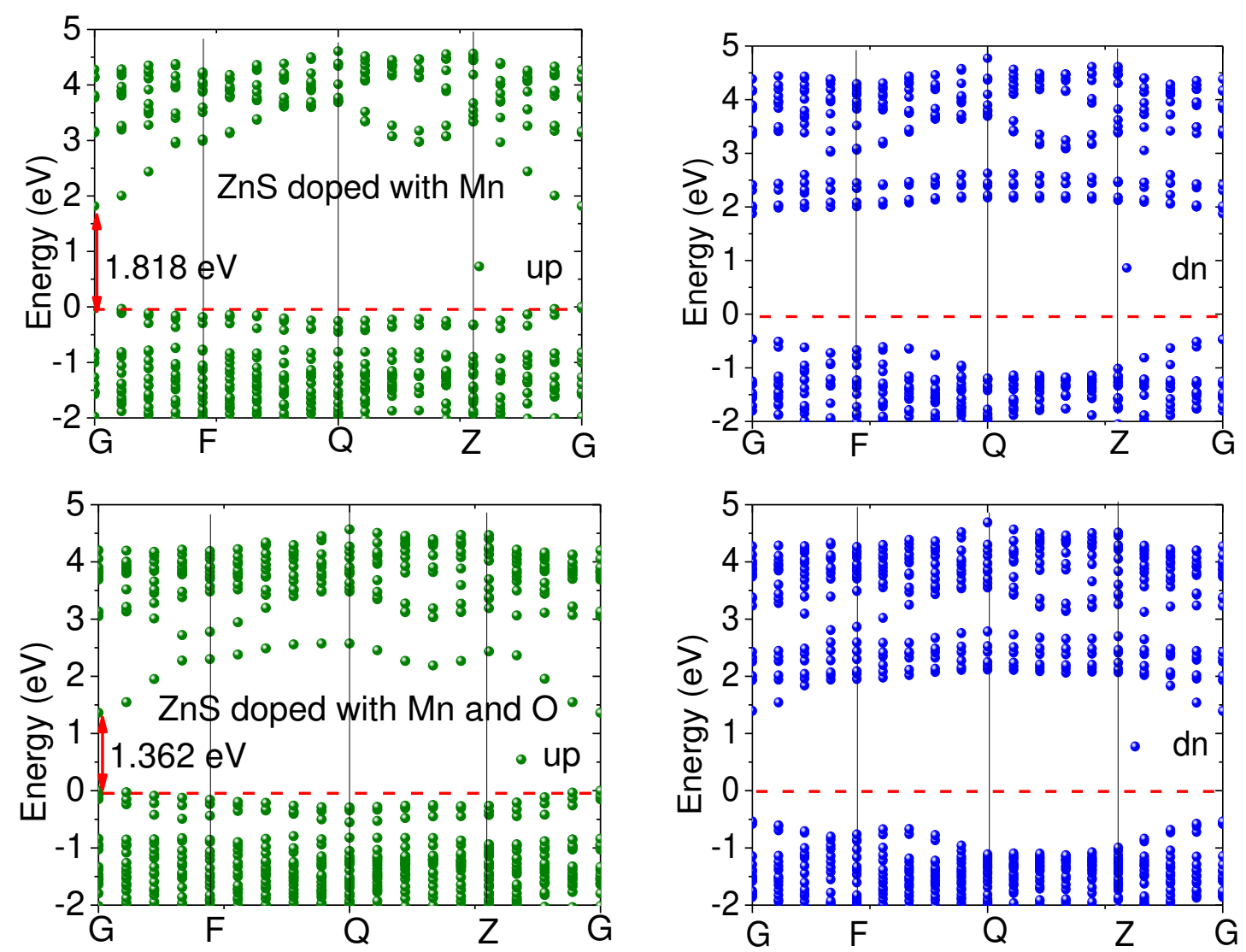

Fig.6. (a) The spin-polarized band structures (up and down) for Mn-doped nano ZnS. 

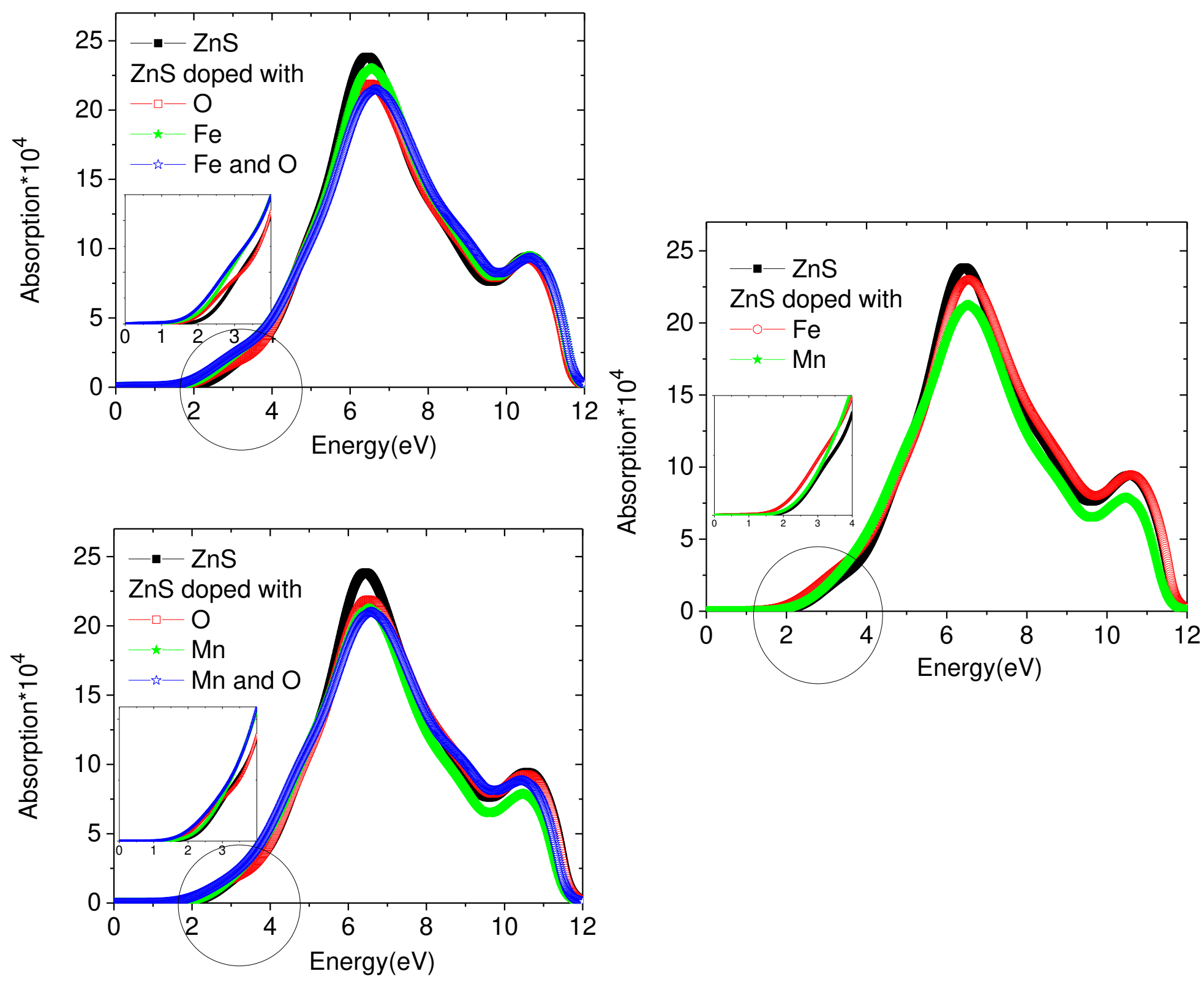

Fig.7. The absorption spectra for undoped and Fe or Mn-doped nano $\mathrm{ZnS}$. 

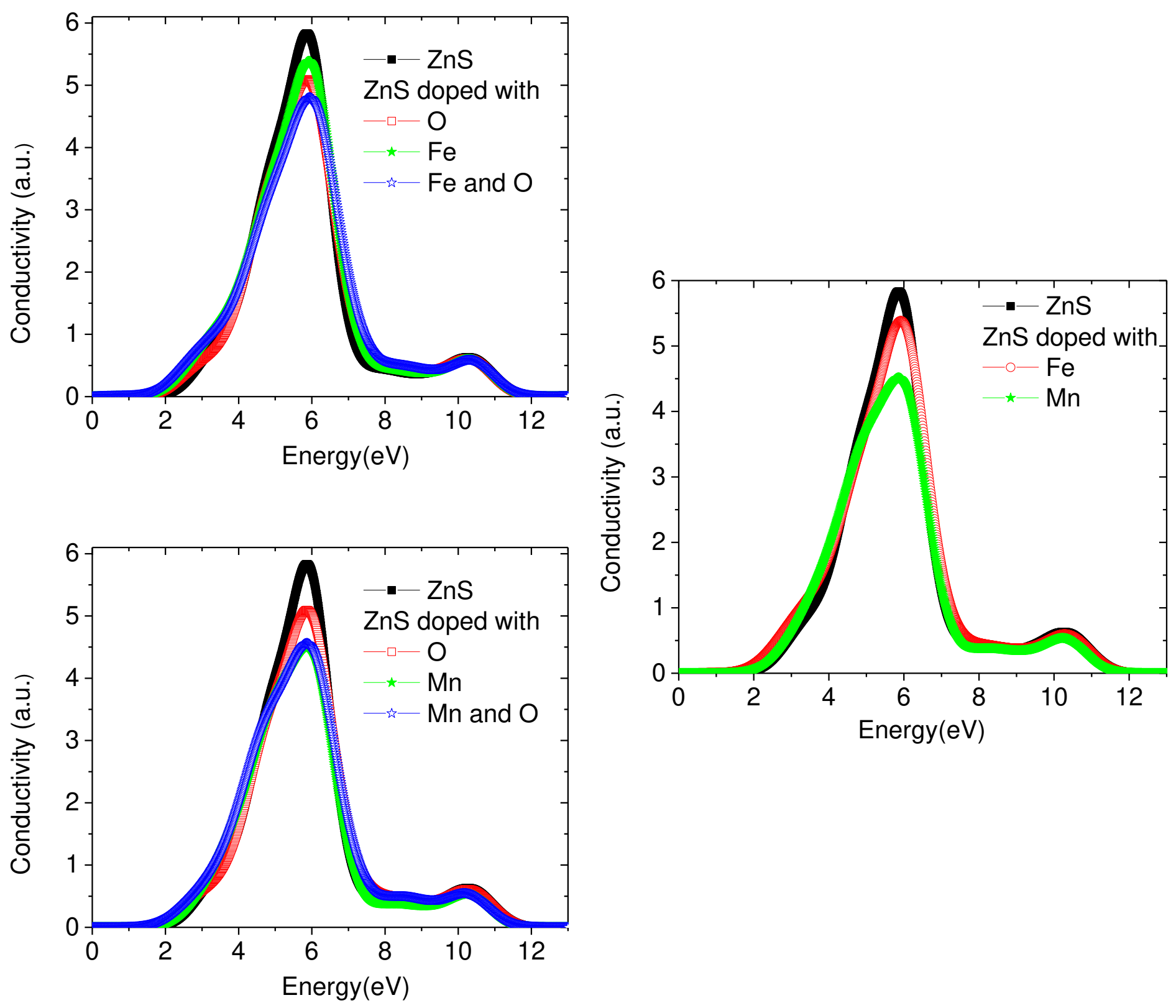

Fig.8. The conductivity for undoped and Fe or Mn-doped nano $\mathrm{ZnS}$. 

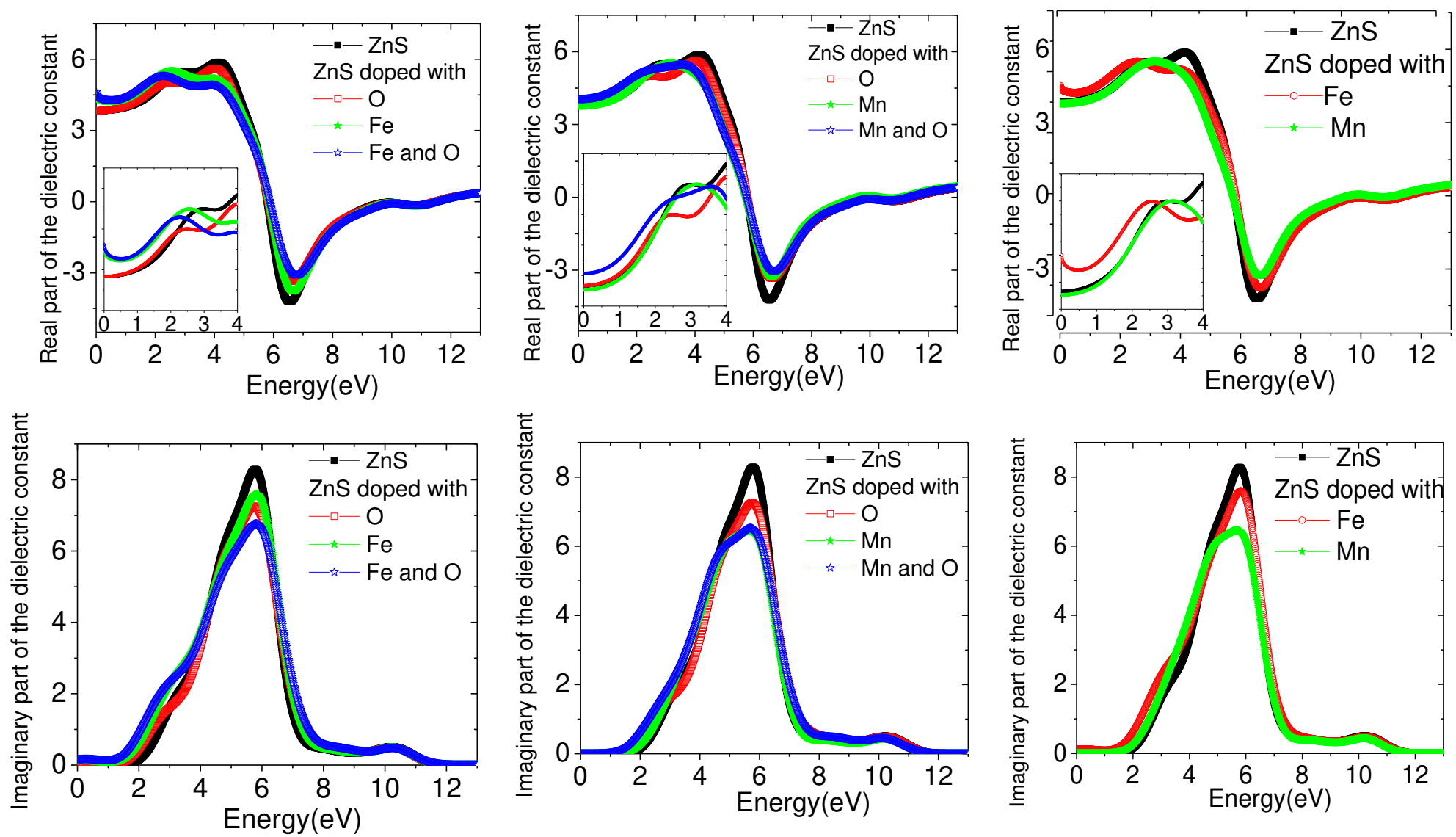

Fig.10. (a-c) real and (d-f) imaginary dielectric parts for undoped and Fe or Mn-doped nano $\mathrm{ZnS}$. 

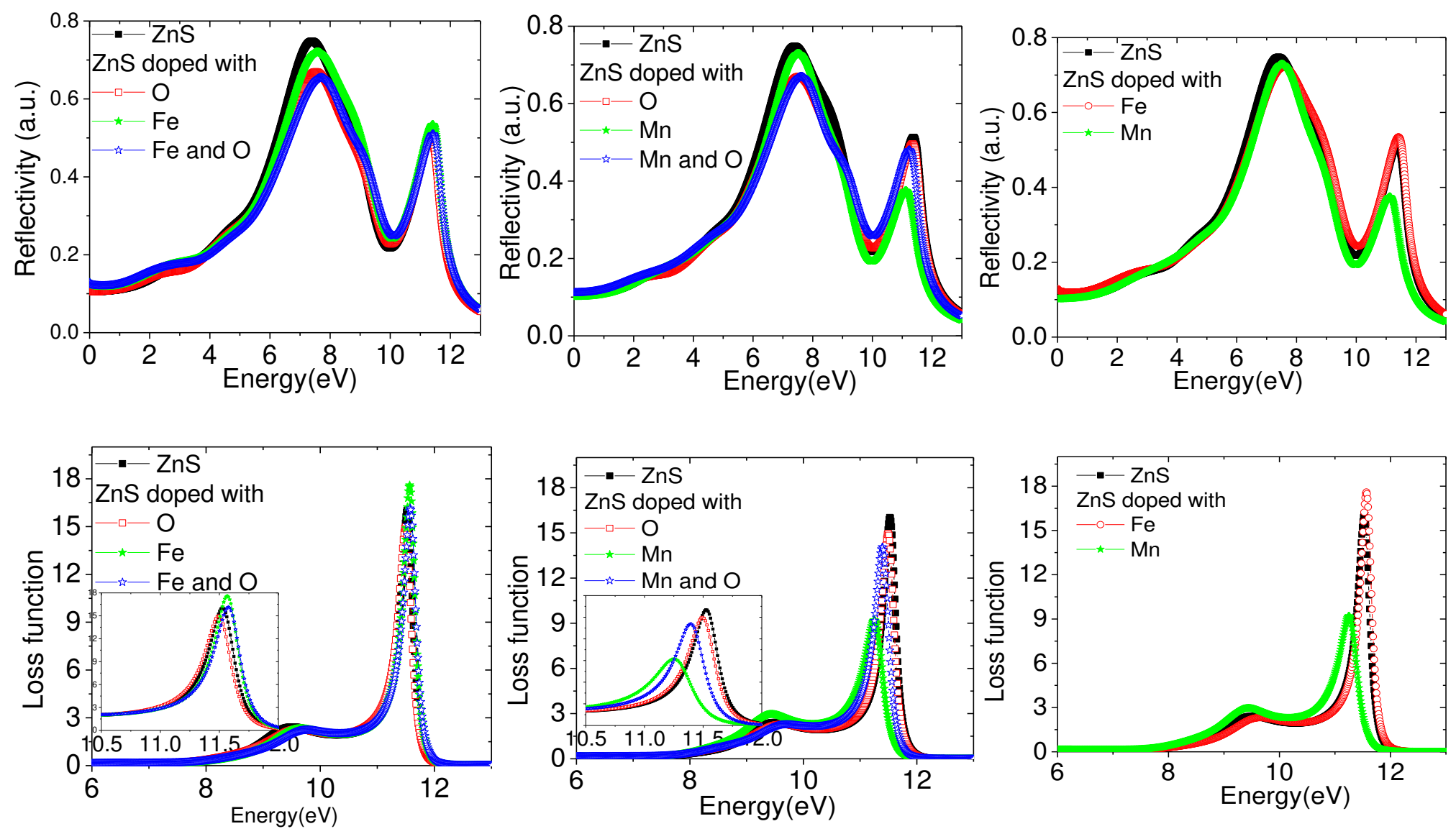

Fig. 11. (a-c) the reflectivity spectra and (d-f) loss function for undoped and Fe or Mn-doped nano ZnS. 
Table1. Lattice parameters (a) $\AA$, average crystallite size (nm), strain and occupancy for undoped and Fe / Mn-doped ZnS samples.

\begin{tabular}{l|l|lll}
\hline \multicolumn{2}{l|}{} & ZnS & ZnS/Fe & ZnS/Mn \\
\hline \multirow{2}{*}{ a (A) } & & $5.3364(1)$ & 5.3500 & 5.3442 \\
\hline \multirow{2}{*}{$\begin{array}{c}\text { size } \\
(\mathrm{nm})\end{array}$} & 111 & 25 & 26 & 26 \\
\cline { 2 - 5 } & 100 & 21 & 20 & 24 \\
\hline \multirow{2}{*}{ strain } & 111 & 0.013 & 0.0068 & 0.012 \\
\cline { 2 - 5 } & 100 & 0.019 & 0.012 & 0.018 \\
\hline \multicolumn{2}{l}{ Occ. } & & 0.048 & 0.051 \\
\hline
\end{tabular}


Figures
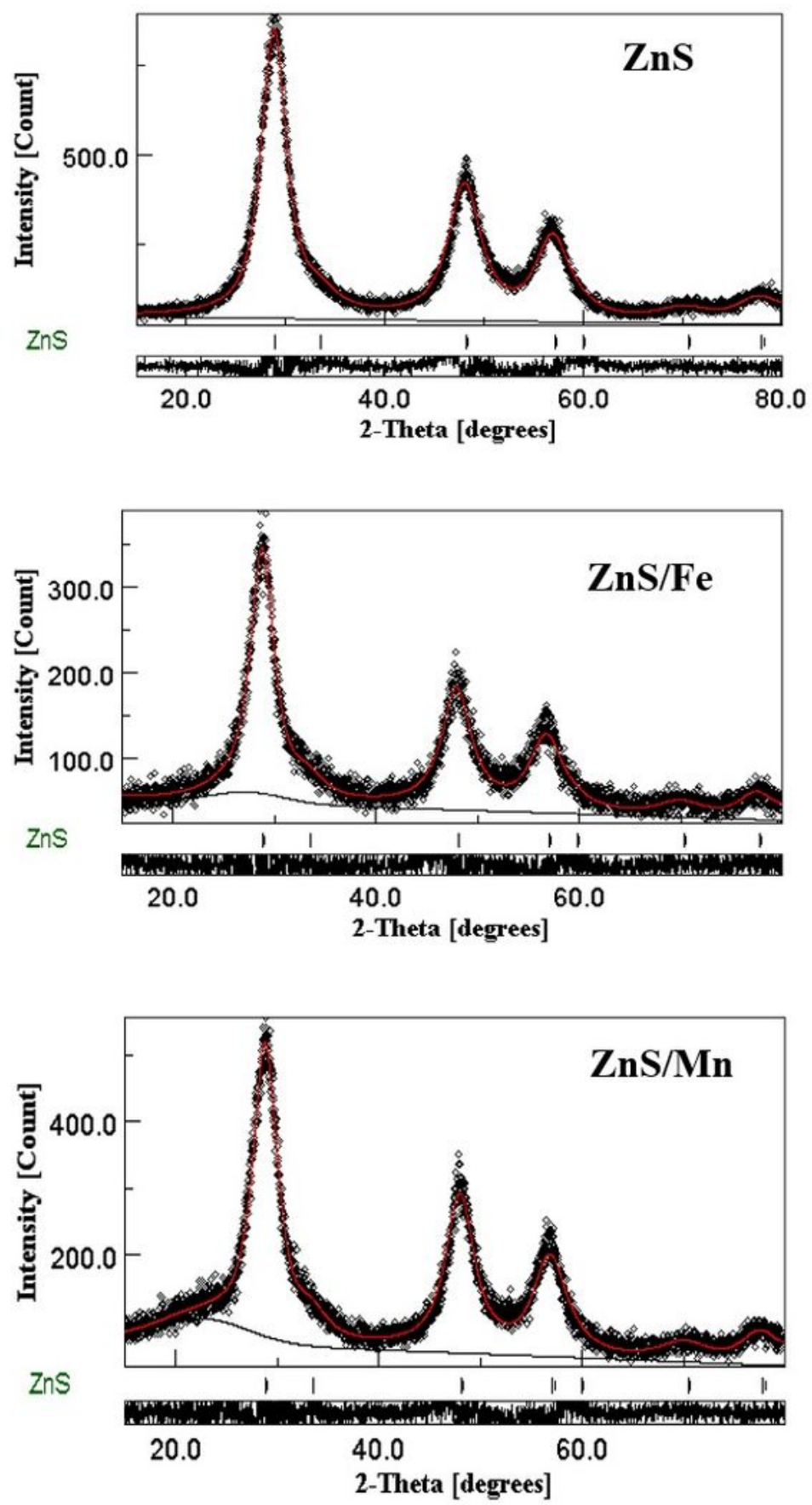

Figure 1

Rietveld refinement for undoped and Fe or Mn-doped nano ZnS. 


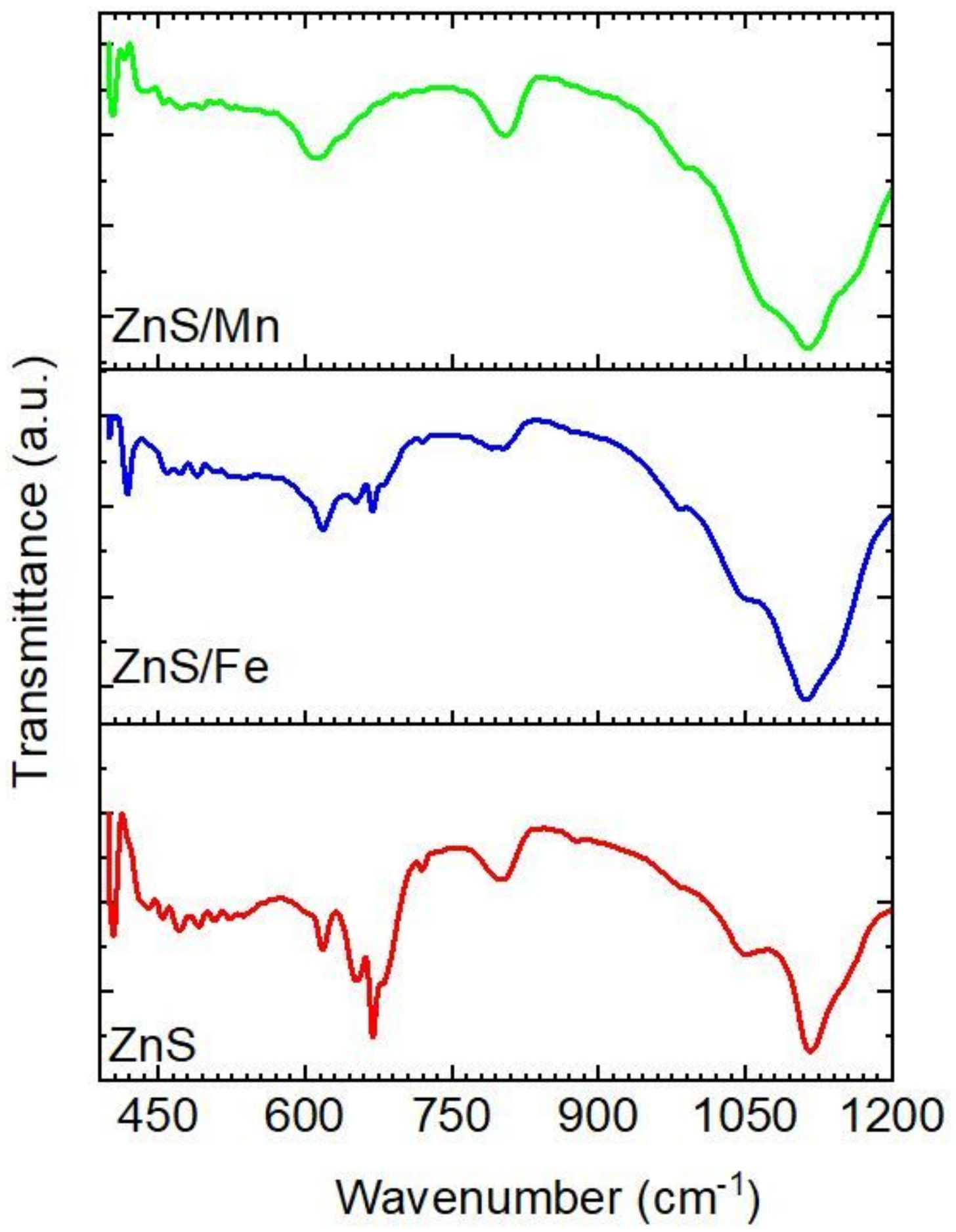

Figure 2

FTIR spectra for undoped and Fe and Mn-doped nano ZnS. 


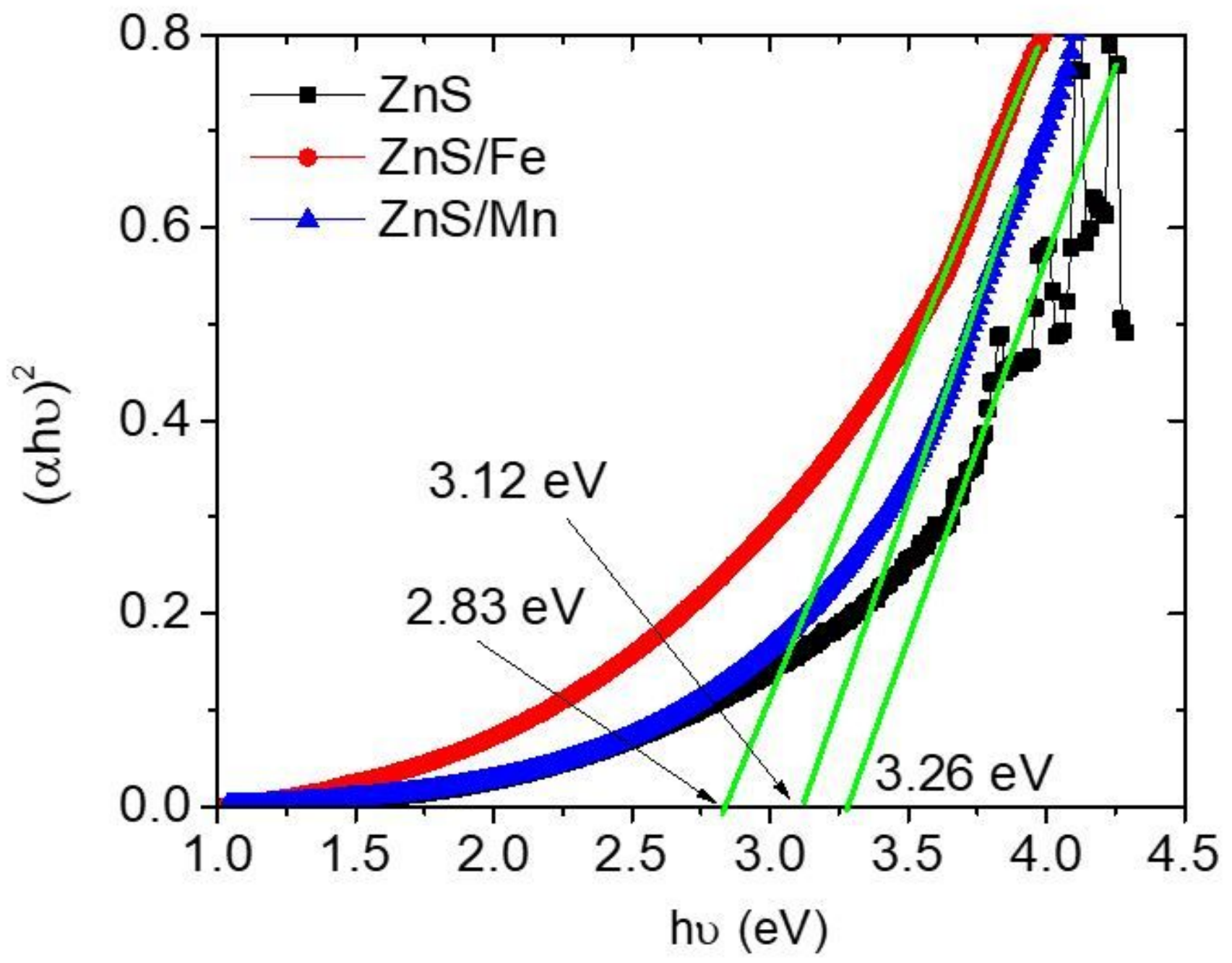

Figure 3

Plots of ((ahu)2) vs photon energy (hu) for undoped and Fe or Mn-doped nano ZnS. 

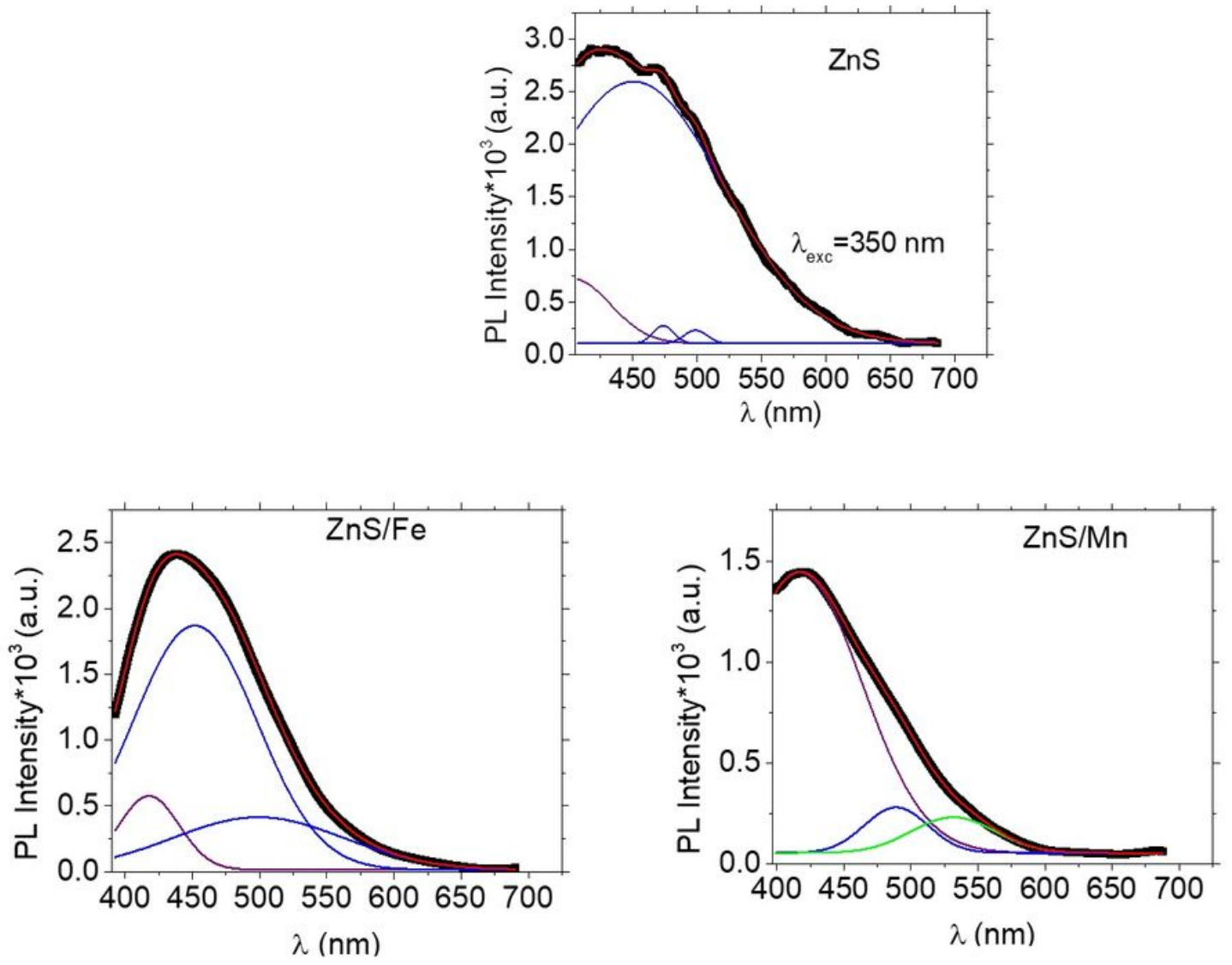

Figure 4

Gaussian fitting for photoluminescence (PL) spectra vs wavelength $(\lambda)$ for undoped and Fe or Mn-doped nano ZnS. 

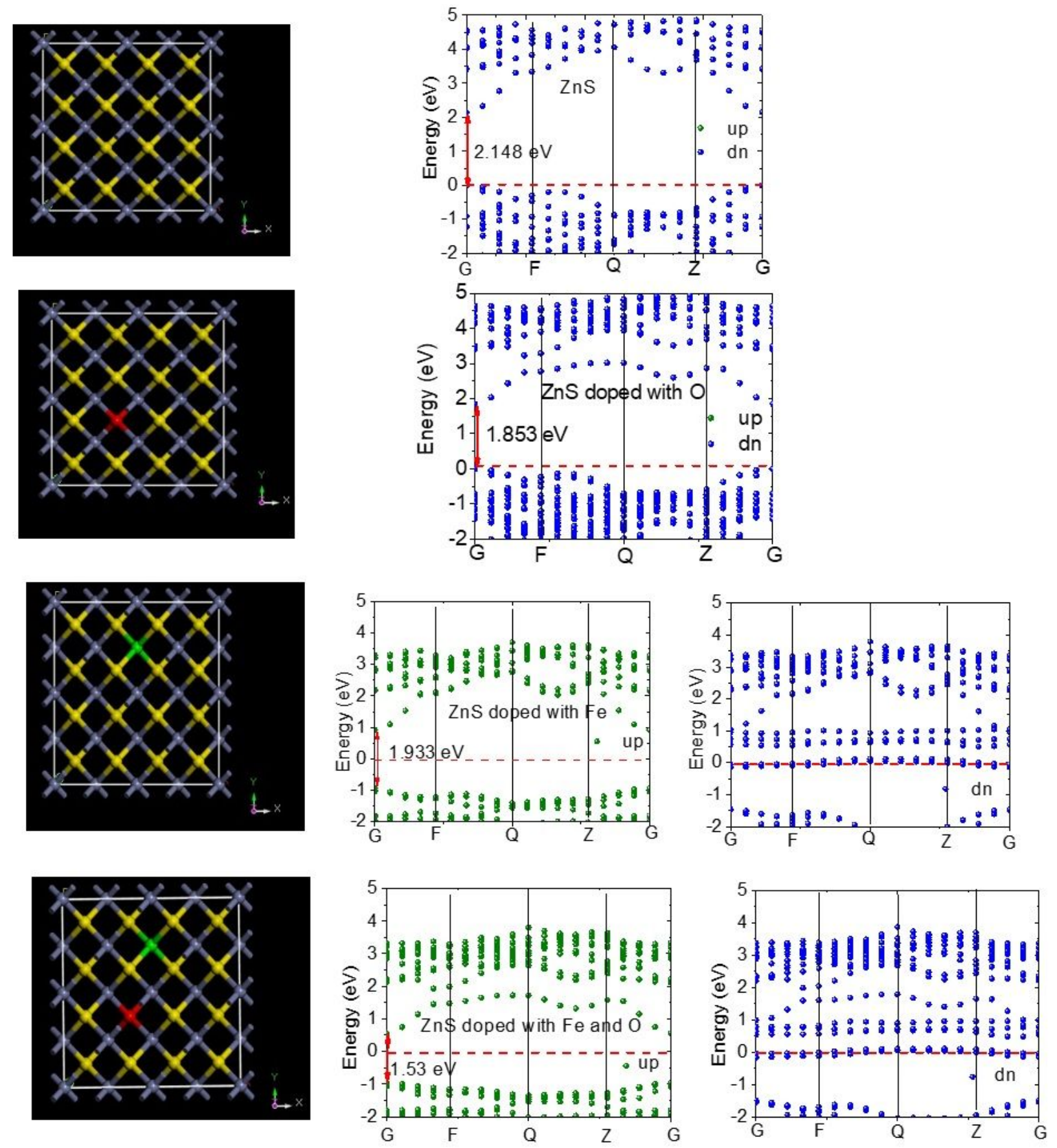

Figure 5

(a) supercells used in the calculation, yellow (red) and violet (green) balls indicate S (0), Zn (Fe or Mn) and (b) the spin-polarized band structures (up and down) for undoped and Fe-doped nano ZnS. 

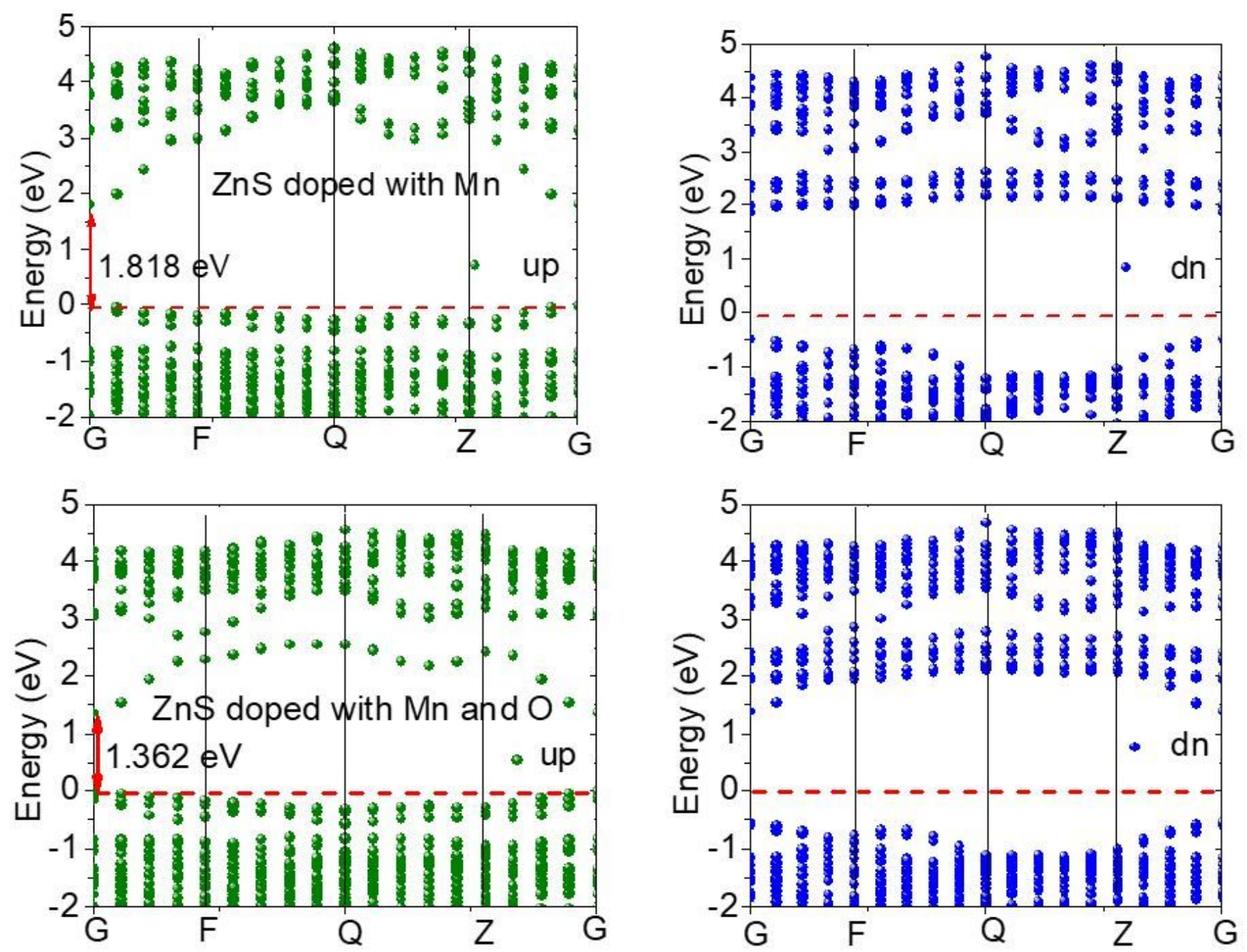

Figure 6

(a) The spin-polarized band structures (up and down) for Mn-doped nano ZnS. 

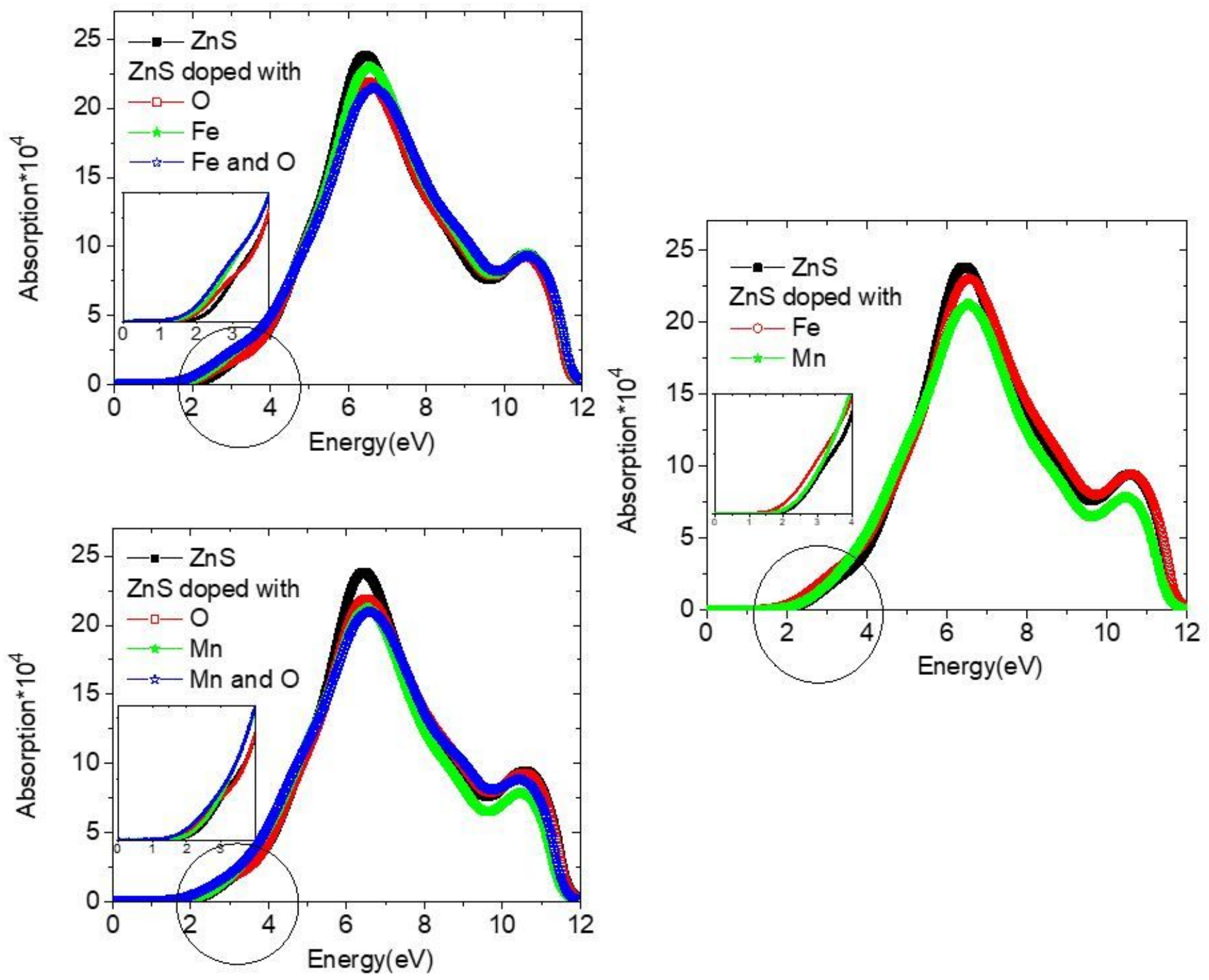

Figure 7

The absorption spectra for undoped and Fe or Mn-doped nano ZnS. 

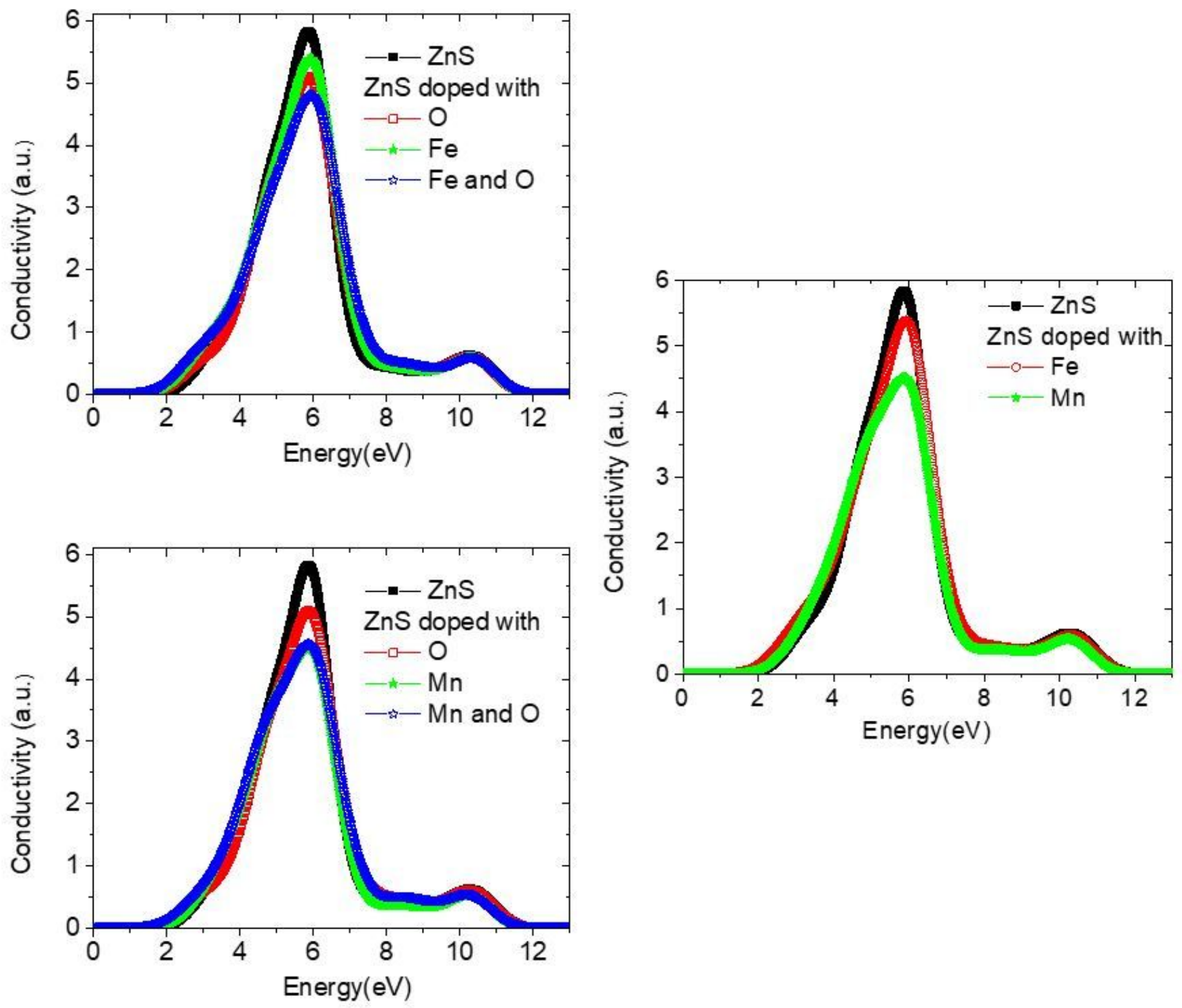

Figure 8

The conductivity for undoped and Fe or Mn-doped nano ZnS. 

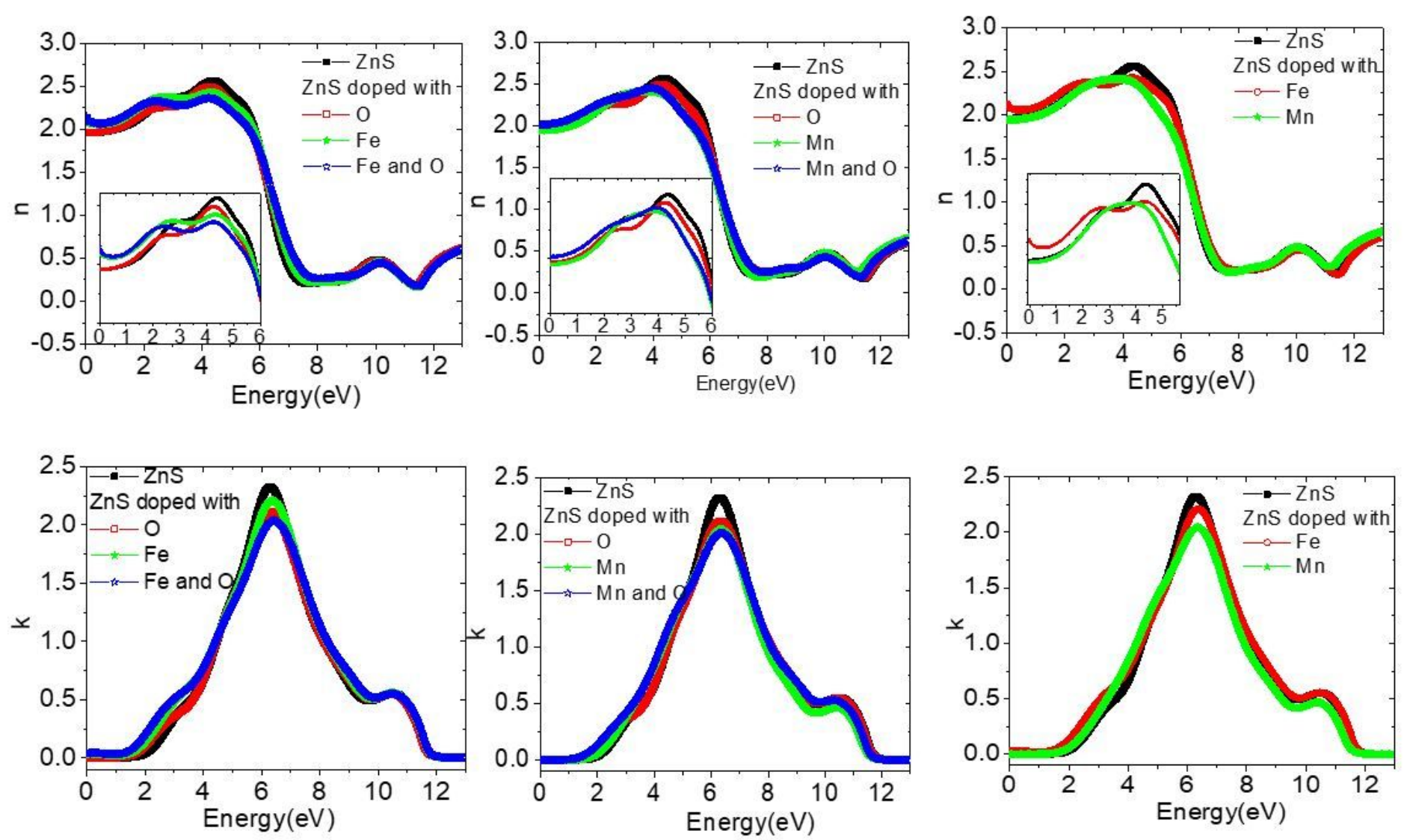

\section{Figure 9}

$(a-c)$ the refractive index $(n)$ and (d-f) extinction coefficient $(k)$ for undoped and Fe or Mn-doped nano ZnS. 

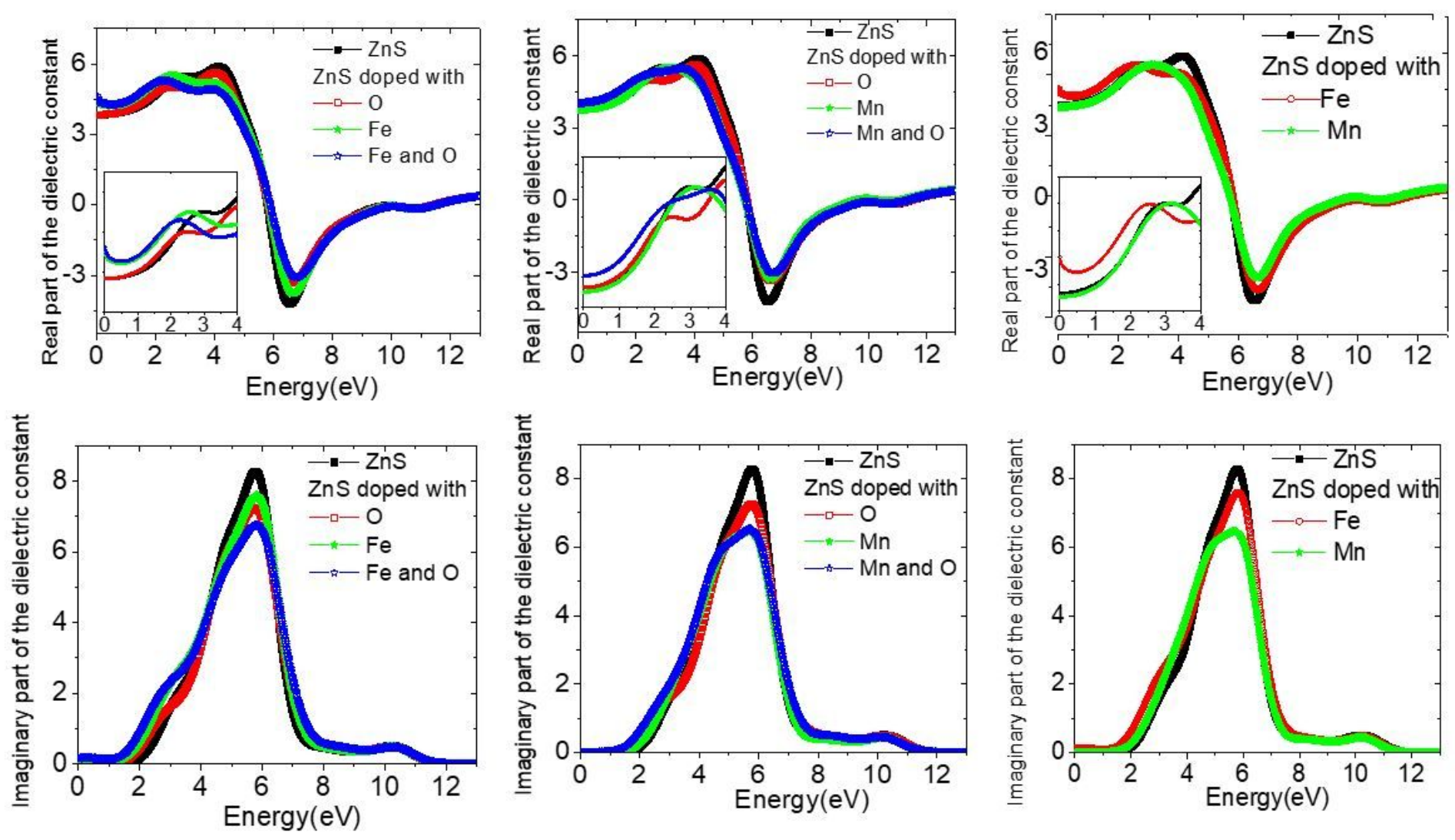

Figure 10

(a-c) real and (d-f) imaginary dielectric parts for undoped and Fe or Mn-doped nano ZnS. 

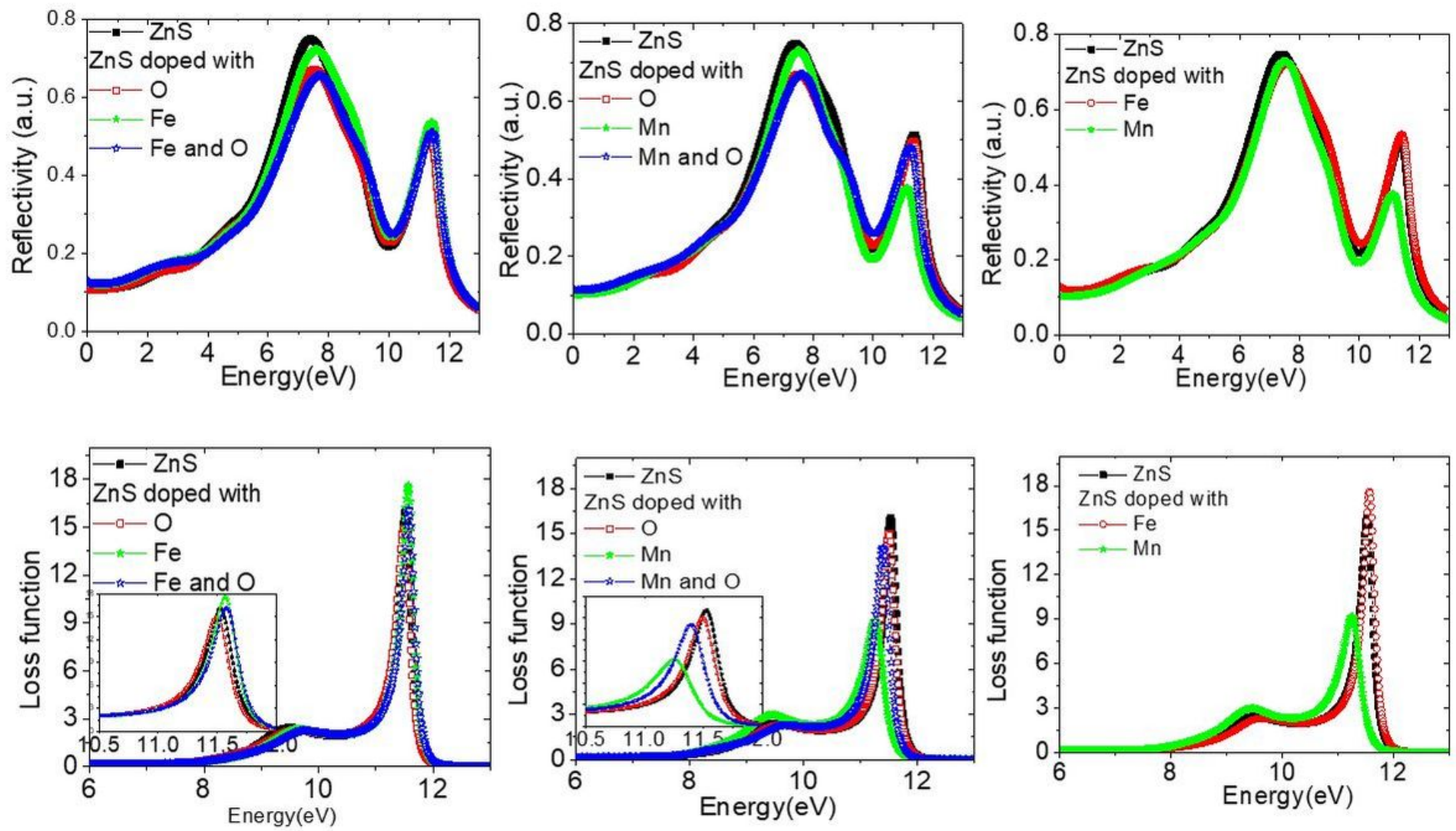

Figure 11

$(a-c)$ the reflectivity spectra and (d-f) loss function for undoped and Fe or Mn-doped nano ZnS. 